Special lecture

\title{
I THE FUTURE OF GLOBAL VACCINE RESEARCH
}

\author{
YOSHIFUMI TAKEDA
}

Faculty of Human Life Sciences, Jissen Women's Univewsity

\begin{abstract}
Vaccines are designed to produce long-term protective immune responses against pathogens and are the most effective medical interventions used to prevent human morbidity and mortality associated with infections diseases. The eradication of the dreaded viral infection caused by human poxvirus is the best success story of how the efficient use of an effective vaccine can eliminate a disease, globally. Dramatic reductions in the incidence of numerous other childhood diseases, such as poliomyelitis, measles and rubella also show the success of efficient vaccines. To date most of the diseases where vaccines have been effective are diseases in which no vectors are involved. A vaccine strategy in diseases in which a vector is involved appears to be considerably more complicated and an outstanding exmaple is malaria. In contrast, enteric diseases like cholera and shigellosis, an effective vaccine should be easier to implement since a vector is not involved in causing the disease and since there are no known animal reservoirs of the
\end{abstract}

causative agent. However, the exact type and quality of immunity afforded by natural enteric infections is still not clearly understood in these enteric infections. Rapid advances in immunology, molecular biology and peptide biochmistry have fostered the development of new approaches in the development of vaccines including the use of peptide vaccines and genetic vaccines. The future to conquer enteric diseases and other infectious diseases will largely depend on how successful the host of new enteric vaccines will be that are being developed using there new approaches. The WHO Vaccine Trial Registry documents an expanding research capacity with an average of 3.9 new studies per year during 1987-1933 rising to 10.7 per year during 1994-2000 with nearly $80 \%$ of these studies being conducted in developing countries. This is a good trend for the future and it is believed that over the next few years effective vaccines will be in place for some of most dreadful infectious diseases.

\section{ALTERED IMMUNE RESPONSES IN MICE WITH CONCOMINTANT SCHISTOSOMA MANSONI AND PLASMODIUM CHABAUDI INFECTION}

\author{
M.TROYE-BLOMBERG \\ Department of Immunology, Wenner Gren Institute, Stockholm University, S-106 91 Stockholm, Sweden
}

Mixed patasitic infections are common in human populations living in malaria-endemic areas. However, little is known how concurrent infections affect the immunity and/or pathogenesis to each other. Protection and elimination of blood-stage Plasmodium chabaudi chabaudi As in resistant mice are characterized by a sequential activation of CD $4^{+}$Th- 1 and Th 2 cells. The patent egg-laying stage of the murine model of Schistosoma mansoni is associated with a strong Th2 response to Schistosoma as well as unrelated antigens. The present study was performed to examine if $S$. mansoni-induced Th2 type of responses would prevent or inhibit the Th1 response required for the early clearance of $P$. chabaudi, thus giving rise to a more severe disease and/ or mortality. Our data show that malaria parasitemias were significantly higher in mice infected with malaria at the time point of a patent egg-laying $S$. mansoni infection. In vitro stimulation with experiments using spleen cells showed that TNF- $\alpha$ production was sighnificantly impaired during the first week of the malaria infection in mice with concurrent $S$. mansoni/P. chabaudi infections. In contrast, the $P$. chabaudi induced Th1 type as measured by IFN- $\gamma$ production, was not affected by the $S$. mansoni infection. Taken together our date suggest that schistosoma and malaria infections profoundly affect each other, finding which might have implications for the development of future vaccines. 


\title{
S-I-1) CHOLERA
}

\author{
SHINJI YAMASAKI
}

Laboratory of International Prevention of Epidemics, Department of Veterinary Sciences, Graduate School of Agriculture and Biological Sciences, Osaka Prefecture University

Cholera is still a fatal disease in developing countries. Among 138 serogroups of Vibrio cholerae only O1 serogroup was thought to have potential to cause epidemic and pandemic of cholera. In 1992, however, a non-O1 V. Cholerae was involved in large outbreaks of cholera in the southern part of Inida. After preliminary serotyping studies, this strain was designated as $V$. cholerae 0139 synonym Bengal. The O139 strain rapidly spread to neibouring countries such as Bangladesh, Nepal, Thailand and China, indicating that this strain had the potential to cause a cholera pandemic.

Since that time we have initiated several collaborative studies with National Institute of Cholera and Enteric Diseases, Calcutta on the molecular epidemiology and characterization of Vibrio cholerae strains isolated from diarrheal patients admitted to ID hospital. Through these studies, we have demonstrated followings, (1) predominant serofroup of $V$. cholerae isolated from the patients through the active surveillance between 1992 to 2000 was O1 serogroup and no O1 serogroup was isolated between January to July in 1993 when O139 was predominantly isolated during this period; (2) O1 V. cholerae isolated after O139 epidemic was not similar to those isolated before O139 epidemics; (3) the $20 \mathrm{~kb}$ region responsible for $\mathrm{O} 1$ antigen biosynthesis was replaced by a $36 \mathrm{~kb}$ fragment carrying the 0139 specific genes in $V$. cholerae $\mathrm{O} 139$ and the $36 \mathrm{~kb}$ gene was most homologous to that in O22 serogroup; (4) the O1 and O139 specific genes were identified and a multiplex PCR, which can simultaneously amplify the ctxA, O1 specific and O139 specific genes was developed; (5) during the course of surveillance non-O1, non-0139 V. cholerae was also isolated from patients with severe diarrhea particularly during certain periods and these strain did not carry any known virulence factors normally present in toxigenic $V$. cholerae $O 1$; (6) antibiotic resistant strains including multidrug resistant and resistance to new quinolones were observed and (7) antibiograms of O1, O139 and non-O1, non-O139 serogroups differed between each other during any given period.

\section{S-I-2) PANDEMIC SPREAD OF VIBRIO PARAHAEMOLYTICUS INFECTION: AN ENTERIC INFECTION SPREAD FROM A TROPICAL ZONE IN ASIA TO THE WORLD?}

\author{
MITSUAKI NISHIBUCHI
}

\author{
Center for Southeast Asian Studies, Kyoto University
}

High incidence of Vibrio parahaemolyticus infection has been reported in the tropical and surrounding areas in Asia since 1996. The research done by our network revealed that it was due to the pandemic spread of $V$. parahaemolyticus infection. We first investigated the reason for a sharp increase in the number of $V$. parahaemolyticus infection in Calcutta in February 1996, and found that the increase was due to the infections by a newly emerged $V$. parahaemolyticus. The new type of $V$. parahaemolyticus was characterized by O3:K6 serovar, possession of the $t d h$ gene, lack of the trh gene, and unique profile of arbitrarily primed PCR. The strains belonging to the same type were detected among those isolated from international travelers coming from three Southeast Asian countries to Japan. Subsequently, we conducted a multinational collaborative study and revealed that infection by the new type of $V$. parahaemolyticus occurred very frequently in Bangladesh, Thailand, Laos, Taiwan, Korea, Japan, and United States. We developed a new PCR method targeting the bases of the toxRS operon unique to the new type of $V$. parahaemolyticus so that it can be detected by this simple PCR method. Examination of many clinical stains by this PCR (named as GS-PCR for group-specific PCR) allowed us to find that the strains belonging to the new type of $V$. parahaemolyticus but exhibiting O4:K68 and O1:KUT serobars emerged in 1998. We named the new type of $V$. parahaemolyticus, including these serovars, a pandemic clone. DNA fingerprinting analyses by pulsed-field gel electrophoresis and ribotyping illustrated clonality of and subtle difference among the pandemic strains. Next, we were able to isolate an O3: K6 
strain belonging to the pandemic clone from bloody clam in Hat Yai City in southern Thailand. A total of 317 strains of V. parahaemolyticus were isolated from diarrhea patients during one-year survey in two hospitals in Hat Yai City in 1999. GS-PCR-positive strains accounted for $75.4 \%$ of the isolated and $80 \%$ of the GS-PCR-positive strains belonged to O3:K6 serovar. The results demonstrated strong relationship between clinical and environmental O3:K6 strains. In addition, GS-PCR-positive strains belonging to three new serovars were detected, indicating emergence of the serovariants in this environment. The new serovariants of the pandemic strains were also detected among the international travelers from Thailand and Viet Nam. We also are examining about 600 clinical strains isolated in Nhatrang, Viet Nam to further expand our study on the epidemiology of the pandemic strains in Southeast Asian countries.

\section{S-I-3) SALMONELLA}

\section{HIDEO HAYASHI}

\section{Department of Infection Biology. Institute of Basic Medical Sciences, University of Tsukuba}

Salmonella causes two major types of infectious diseases, enteric fever and food poisoning. The enteric fever is common in tropical countries from where travelers got infected and bring into the developed countries. According to the census of NIID, Japan, the reported cases of enteric fever in Japan was 148, during the period from April '99 to November '00. Among the cases, 108 (73\%) were imported from tropical countries and the infected patients were almost men at their age of 20's. On the contrarily, salmonellar food poisoning which causes limited enteritis in man has been the most common in developed countries. Salmonella has been the top ranked food poisoning causative agent for many years in Japan. S. Typhimurium and S. Enreritidis have been the common agents but, in 1999, there happened a diffuse out break by $\mathrm{S}$. Orenienburg that spreadded through dried squid-snack. We examined the specificity of the outbreak strains. The genomic pattern by PFGE was identical among the outbreak isolates but different from those isolated in Thailand and the isolate from the environment. The outbreak isolates had a couple of small plasmids and this was specific among the isolates from Ibaragi prefecture. The function of the plasmids are under investigation, but the reason why this train caused sudden out break has not been clarified.

Genus Salmonella contains more than 2,000 serotypes and ranges over variety of hosts from lower reptiles to higher primates. The virulent factors are also very diverese: it has almost all of bacterial virulence factors such as, adhesin, invasin, impedin aggressin, modulin and secretable enzymes. Those natures make it difficult to identify patho- genic strains to human with a simple and rapid method. The whole genome analysis was thought to be the most efficient method to solve those complex problems. The nine of the prototype strains have been subjected to the whole genome analysis but so far none of them is publicized as yet. The problems seem to lie in the variety or the flexbility of the genome structure and the complexity of regulatory mechanism of the gene expression. The five kinds of pathogenicity islands have been characterized but the relation to the serotypes or the distribution among the species are still indistinct. To prevent Salmonella infection, it needs a specific detection/identification method for human specific virulence factors.

We have been challenging to solve these problems by some different approaches: genetic analysis and identification of human specific virulent genes, detection of the specific gene by rapid PCR, identification of serotype specific genes by DNA chip and rapid PCR method, development of ELIZA for detection of enterotoxin in foods and clinical samples. With the application of gene subtraction method, we had been detecting human specific virulent genes and isolated seven of $2 \mathrm{~kb}$ DNA fragments of which function remain to be identified. The developed methods mentioned above were briefly introduced.

This study was carried out by the cooperation with, $\mathrm{H}$. Kurazono, Okayama University, S. Makino, Obihiro Veterinary College, S. Nakayama, NIID Japan, W. Chaicumpa, Mahidol University, P. Sudarmono, University of Indonesia, T. Kumao and W. Ba-Thein, University of Tsukuba. 


\title{
S-II-1) IMPORTANCE OF ACUTE RESPIRATORY INFECTIONS (ARI) IN TROPICAL AND DEVELOPING COUNTRIES
}

\author{
KAZUNORI OISHI, HIROYUKI YOSHIMINE, AND TSUYOSHI NAGATAKE
}

Department of Internal Medicine, Institute of Tropical Medicine, Nagasaki University

Acute respiratory infections are common causes of morbidity and mortality in tropical and developing countries. A changing pattern of these diseases has, however, been recognized especially in Sub-Saharan Africa, where there is a high seroprevalence of HIV infection.

A hospital-based prospective study on a total 99 patients with community-acquired pneumonia (CAP) was carried out in Kampala, Uganda between 1996 1998. We evaluated the microbiological etiologies, clinical features and effectiveness of short-term parenteral ampicillin followed by oral amoxicillin for these patients according to HIV-status. We demonstrated a very high prevalence (74.8\%) of HIV-1 infection. No significant difference was observed with respect to age, gender, prior antibiotic usage, symptoms, laboratory data or bacterial etiology between HIV-1-infected and HIV-uninfected CAP patients. Most of
Streptococcus pneumoniae (19 strains) and Heamophilus influenzae (8 stains) isolated from HIV-1-infected patients were penicillin-resistant $(94.7 \%)$ and b-lactamase producing $(75.0 \%)$ stains, respectively. We, however, found a high percentage of good clinical response both in HIV-1-infected (81.3\%) and HIV-uninfected $(85.7 \%)$ among 39 patients with CAP due to bacterial pathogen. In addition, we documented a clinical feature of fifteen cases of recurrent bacterial pneumonia among $101 \mathrm{HIV}$-infected persons with CAP between 2000 2001. The mean CD4 levels of these patients were found to be $192 / \mathrm{ml}$, and the mean interval between the first and the secound episode was 155 days.

Our present date suggest a clinical importance of bacterial CAP among HIV-infected persons and usefulness of short-term parenteral ampicillin therapy for these patients in HIV-endemic, developing countries.

\section{S-II-2) VIRAL ACUTE RESPIRATORY INFECTIONS IN TROPICAL COUNTRIES-FOCUS ON INFLUENZA VIRUS INFECTIONS-}

\author{
SUZUKI HIROSHI
}

Department of Infectious Disease Control and International Medicine,

Niigata University Graduate School of Medicine and Dental Sciences

Respiratory infections are the most common afflictions of humans, and mostly are caused by viruses. Children contract on average about half a dozen respiratory illnesses each year, and adults perhaps two or three. While many people consider influenza to be a minor disease, this may be due to be a minor disease, this may be due to confusion in the diagnosis. Symptoms of influenza resemble those of other infections and the term is often misapplied to a range of minor upper respiratory tract infections as a respiratory syndrome. More over, episodes of bacterial pneumonia, and worsening of underlying conditions, may not be recognized as being a consequence of prior influenza virus infections. Laboratory diagnosis is essential to verify the circulation of influenza viruses, and to generate reliable date on morbidity and mortality, especially in tropical or subtropical regions.

In most tropical subtropical regions, laboratory- confirmed influenza can occur throughout the year, with peaks of increased activity once or twice each year. When influenza may be not noticed because of a lower peak demand on health services. Furthermore, there were quite limited epidemilogical date of influenza infections in these regions due to lack of laboratory personnel and equipment.

Viral isolation is a basic and important technique in the field of virology despite the development of moderm techniques. One cell line can only culture a limiting numbers of these respiratory viruses, and has made it difficult to use the virus isolation as a routine method for laboratory diagnosis and epidemiological work of acute respiratory infections (ARI). In order to overcome this difficulty, we used the microplate method for virus isolation, which utilizes five cell lines and thus covers a wider range of respiratory viruses. Application of the method contributes to the routine diagnosis and helps define the epidemiology of viral ARI. 
As influenza has consistently been associated with excess mortality and observed mainly in patients aged 65 or older, influenza vaccines are strongly recommended in countries for those persons who are at increased risk of complications. Hong Kong and Taiwan have influenza vac- cination program for elderly people, but not other Southeast Asian countries. In more then 1 peak of influenza occurs each year, we need to study the appropriate timing of vaccination and selection of the vaccine formation.

\title{
S-II-3) BURDEN OF HAEMOPHILUS INFLUENZAE TYPE B (HIB) DISEASES IN BANGLADESH
}

\author{
SAMIR K SAHA ${ }^{1}$, M. HANIF ${ }^{1}$, M. RUHULAMIN ${ }^{1}$, K. MATSUMOTO ${ }^{2}$, K. OISHI ${ }^{2}$, T. NAGATAKE ${ }^{2}$ \\ ${ }^{1}$ Bangladesh Institute of Child Health, Dhaka Shishu (Children) Hospital, Dhaka-1207, Bangladesh. \\ ${ }^{2}$ Department of Internal Medicine, Institute of Tropical Medicine, Nagasaki University, Nagasaki, Japan.
}

The virtual elimination of Haemophilus influenzae type $\mathrm{b}$ (Hib) disease from industrialized countries by vaccine is a moderm public health triumph. However, the disease is still prevalent in the developing part of the world, where the vaccine is not available, and causes invasive diseases like pneumonia, meningitis etc. Hib diseases cause 12.9 million deaths per year in under five children and most of them are in the nonindustrialized countries. In the recent years, the problem is further aggravated due to the emergence of multidrug resistant Hib strains. Surveillance on burden of Hib diseases is focused on meningitis cases as the diagnosis is straight forward and can yield a very accurate estimates of over all burden of the disease.

In the study period, from 1994 to 2000,338 invasive strains of $H$. influenzae were isolated from blood and CSF of pneumonia and meningitis cases respectively. $H$. influenzae was the most predominant $(50 \%)$ among the isolates followed by S. pneumoniae (32\%), and $97 \%$ of the all $H$. influenzae isolates were type $\mathrm{b}$ (Hib). A vast majority $(91 \%)$ of Hib infections were found in first year and only few $(2 \%)$ after 2 nd year of life.

Over all $35 \%, 54 \%$ and $16 \%$ of the strains were resistant to ampicillin, cotrimoxazole and chloramphenicol re- spectively. Most (95\%) of the ampicillin resistance was due to data-lactamase production, as detected by nitrocefin disk, and the MIC level these strains were $>256.0 \mathrm{ug} / \mathrm{ml}$. Cotrimoxazole resistance showed an increasing trend with peak $(64 \%)$ in 1996 and then declined to the level of $33 \%$ in 2000. Resistance to ampicillin remained similar through out the study period (range $33 \%$ to $43 \%$ ). The most notable finding was the emergence of resistance to chloramphenicol in $1996(5 \%)$ and its increasing trend in the subsequent years, which reched to the level of $40 \%$ in 2000 .

Meningitis caused by Hib resulted death in $34 \%$ and similar number were survived with sequel. Eighty four percent of the children with Hib diseases were from very poor families who cannot afford to buy the medicines and vaccines for treatment and prevention respectively.

These findings has paramount implications in child health as cotrimoxazole is recommended by WHO for pneumonia, at the community level, and ampicillin and chloramphenicol is the most available and widely used antibiotics in the hospitals of this country. Lastly, the predominance of Hib in causing invasive diseases and emergence of resistance among them strongly indicates the need of introduction of Hib vaccine in EPI program of Bangladesh. 


\title{
S-III-1) RECENT DEVELOPMENTS IN HIV/AIDS RESEARCH
}

\author{
TAKASHI KITAMURA
}

Director Emeritus, Nattional Institute of Infectious Diseases/Toyama Institute of Health

"Panel on AIDS" of US-Japan Medical Science Program (CMSP) has been working with US Panel to combine the research activities and achievements on HIV/AIDS carried out in both United States and Japan. As the Japanese Panel chair, the speaker has been watching the developments of global HIV/AIDS pandemic and researches to fight against it. Here, as the first speaker of the session, I would like to present the recent developments in HIV/AIDS pandemic and researches in various aspects against it.

1) Epidemiology; AIDS was recognized in 1981 by US-CDC. By its excellent studies based on surveillance it could identify several key risk factors by March 1983, before the discovery of causing virus by Montagnier in May 1983. By the end of 2000, estimated 36 million people have been infected with HIV, more than $70 \%$ clustering in sub-Saharan Africa. Number of AIDS orphans, children lost both parents due to HIV, is increasing rapidly in many developing countries.

2) Blood safety; Safety of the blood supply has been ensured by the donor screening based on the detection of HIV antibody. There is "acute infection phase", a few weeks after HIV exposure, where relatively high level of viremia makes the donor highly infectious despite the "sero-negative" test results. To close such "window period", viral nucleic acid testing has been introduced in Japan to close the "window" by nearly $30 \%$.

3) Vaccine development; Retroviruses have "latent infection period" as a part of regular replication cycle and, during this period, HIV-infected cells can escape the surveillance of immune mechanisms, resulting in the theoretical difficulty of vaccine development. Recently Prof. Kiyono's group identified "common mucosal immunity" among various mucosal compartments. Nasal immunization of animals could induce vaginal immunity against recombinant virus with HIV/SIV genes.

4) Chemotherapy; Retroviruses from an exceptionally "chemotherapy-prone" virus group. They have in their replication cycle several specific steps vulnerable to drug interventions. Successful developments of reverse transcriptase and protease inhibitors substantially improved the prognosis of HIV/AIDS patients, reducing the progression of HIV disease and death by AIDS. Mother-to-child tansmission are effectively prevented and occupational exposures can be managed by chemotherapeutic regimens.

5) Transmission; Transmission efficiency has been studied quantitatively by assay of viral RNA genome loads. Risk of being infected by single episode of heterosexual contact is estimated to be $0.05-0.15 \%$ (infection after 700 2000 contacts). Ulcerous or inflammatory lesions in the genital mucosa enhances the risk of HIV transmission. Genetic deletion of a co-receptor, CCR5, expression make the individual HIV-resistant.

6) Prevention; UNAIDS put the prevention of general STDs as the most effective preventive approach against HIV infection. Human trial of "topical vaginal microbicide" containing spermicidal contraceptive enhanced the HIV transmission by nearly $50 \%$, possibly due to inflammatory changes in mucosa caused by unexpectedly frequent applications.

7) Molecular epidemiolgy; HIV can be identified with subtypes (clades) based on base sequences of individual genes. With the time after the introduction of multiple subtypes of HIV in circulation within a region, increasing variety of recombinants were identified. Now the circulating HIVs are described by CRF (circulating recombinant form) designation.

8) Drug resistance; Resistances to various antiretroviral drugs are idetified as the mutations in pol genes. Diagnostic tests to identify the infectious viral genomes and possible resistance mutations in the sequence are being developed, in response to the need of effective therpeutic design. 


\title{
S-III-2) RESEARCH AND DEVELOPMENT OF RECOMBINANT HIV VACCINE-PRE-CLINICAL TRIAL
}

\author{
HONDA M., NAKASONE T., MATSUO K., IZUMI Y., HAMANO T., OHSU T., TAKIZAWA M., \\ SOMEYA K., KaIZU M., HARA T., KaWAHARA M., HORIBATA S., KENEKIYO M., HAMATAKE M., \\ AMI Y., SAKAI K., SHINOHARA K., SAKAKI Y., KURATA T., YAMAZAKI S., AND YAMAMOTO N.
}

\section{National Institute of Infectious Disease}

In controlling the HIV infection, preventive HIV vaccine would be of great use, when it was developed efficaciously. Recent considerable progresses have shown that correlates of protective immunity may due to interaction of immunological, viral and genetic factors. Furthermore, high levels of the cellular and humoral immune reponses are probably responsible for controlling the viral loads that limit HIV infection and progression of diseases. Mycobacterium bovis bacillus Calmette-Guérin (BCG) and a vaccinia viral strain that trageted in this HIV vaccine development are considered to be the appropriate HIV vaccinevector that satisfy the requirements for HIV vaccine use for human, when it would induce high levels of HIV-specific immunity with maintaining BCG immunity against tuberculosis. The prime-boost vaccine regimen significantly protected all the animals from high levels of palasma viral load and $\mathrm{CD}^{+}$cell loss: a decline in HIV1 set-point levels was more than hundred times and $\mathrm{CD}^{+}$cell decline was also significantly reduced. This approach induced similar levels of immunity-specific for HIV-1 Gag in animals consecutively primed with $\mathrm{rBCG}-\mathrm{HIV} / \mathrm{Gag}$ (80 $\mathrm{mg}$ orally or $0.1 \mathrm{mg}$ intradermally) and boosted with rDIs HIV/Gag. Since the vaccine regimen is revealed to be very safe, these studies suggest a strategy for enhanced induction of T-cell mediated protective immunity to HIV-1.

\section{S-III-3) TREATMENT OF AIDS}

\author{
MASAKAZU HATANAKA
}

Kyoto University, Kyoto and Shionogi Laboratory, Osaka, Japan

AIDS, acquired immunodeficiency syndrome, is caused by infection of a retrovirus called HIV, human immunodeficiency virus. HIV encodes three enzymes, reverse transcriptase, protease and integrase, whose inhibition is the targets of AIDS treatment.

First, nucleoside analogs has been developed as inhibitors of reverse transcriptase followed by non-nucleosides. As non-nucleoside-inhibitors are less expensive compared with nucleoside analogs, developing countries may afford their use for the treatment of AIDS and prevention of mother-to-child infection of HIV. Although the onset of resistant strains of HIV towards reverse transcriptase is inevitable by long duration of treatment course, adequate use and change of drugs may lead long threapeutic effects. Protease inhibitors have been developed by mainly molecular design- ing and are quite effective against resistant strains of reverse transcriptase inhibitors and presently combination of three drugs against reverse transcriptase and protease is a major stream of treatment of AIDS called HAART (highly active anti-retroviral therapy). At the first time, we have developed an inhibitor of HIV integrase (S-1360), which is under a clinical trial in USA and is expected to be soon available for the AIDS patients. In developing countries of Africa and Asia, HIV infection is in the midst of its pandemics and is urgent to take action of its prevention and treatment, which is alerted as emergency by United Nations and WHO. Developed countries including Japan are now taking actions urgently towards this target in many extensive ways including medical and financial supports. 


\title{
S-IV-1) TRIALS AND PROSPECTS OF EPIDEMIOLOGICAL SURVEY FOR BABESIOSIS IN JAPAN AND MALARIA-ENDEMIC AREAS
}

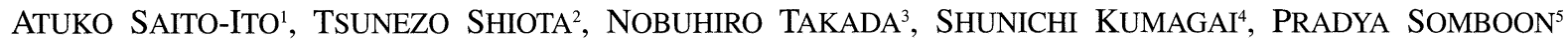

\author{
Section of Parasitology ${ }^{1}$ and Division of Clinical Pathology and Immunology ${ }^{4}$, Kobe Univ. \\ Graduate School of Medicine, Department of Medical Zoology, Kyoto Prefectural University of Medicine ${ }^{2}$, \\ Department of Parasitology, Fukui Medical University ${ }^{3}$, \\ Department of Parasitology, Chiang Mai University Faculty Medicine ${ }^{5}$
}

Babesiosis is tick-transmitted intraerythrocytic protozoan disease of animals and occasionally occurs in humans. Most cases of human babesiosis have been caused by Babesia microti, a species of rodents. Cases by B. microti have been reported nearly exclusively from the United States. In 1999, we confirmed the first human babesiosis case in Japan. It was demonstrated that the case had been infected by the blood transfusion from an asymptpmatic donor infected with $B$. microti-like parasites. The sequence of SSUrDNA of parasites isolated from the patient (Kobe srtain), however, was distinct from that of B. microti of the United States origin (Gray, GI and AJ strains) nor that of parasites isolated from wild rats in Otsu where $B$. microti-like parasites were first demonstrated in wild rats in Japan (Otsu strain), although they have the higest homology to one another. Antigenicities of Kobe strain, Otsu srtain and the strains of US origin are also different from one another.

In these circumstances, we examined antibody-titers against Kobe strain by IFAT for 995 sera in 2000 and 499 sera in 1981 of outpatients of hospitals in Hyogo under informed consent. Three sera2000 and one in 1981 showed to be positive at $\geqq x 518$ including two positive at $\geqq x 4096$. One serum postive at $\geqq x 518$ showed no cross reactivities against Otsu strain or $P$. yoelii like the sera of the first patient and the asymptomatic donor. By western blot analysis, it also detected the antigen of the same size (ca. $40 \mathrm{kD}$ ) as that for the sera of the first patient and the asymptomatic donor. Thus, it was suggested that at least one outpatient, the donor of the serum, had experienced the actual infection with Kobe strain. However, three sera that showed cross reactivities against Otsu strain and $P$. yoelii could be falsepositive. Specificities of IFAT should be reconfirmed.

In the field survey of rats and ticks for Babesia infection in Hyogo in 2000-2001, it was showed by microscopic observation of smears or PCR that 5 of 9 rats were $B$. microti-positive in Rokko area, and all 5 were Otsu type. In Awaji island, 6 of 22 rats were B. microti-positive, and 4 were Kobe type and 1 was Otsu type (1 was not detemined). Morever, the probable SSUrDNA of B. microti was amplified from a salivary gland of a tick of Ixodes ovatus collected in Rokko. Its sequence has the highest homology with those of Kobe, Otsu and US type, but different from any of them. It was suggested that $I$. ovatus has some roles in transmission of $B$. microti.

In the field survey of rats for Babesia infection in Chiang Mai, Thailand in 2000, Babesia-like parasites were identified in 6 of 9 of Bandicota indica. The sequence analysis of the parasites showed that the parasites are more closely related to $B$. canis and $B$. divergence than $B$. microti. Although futher studies are necessary, the emergence of human babesiosis should be considered in malaria endemic areas.

\section{S-IV-2) NOVEL STRATEGIES FOR TICK CONTROL}

\author{
KOZO FUJISAKI
}

National Research Center for Protozoan Diseases, Obihiro University of Agriculture and Veterinary Medicine

Ticks are ectoparasites found in almost all parts of the world. While mosquitoes trasmit most of the important human pathogens such as malaria and yellow fever, ticks surpass all other arthropods in the number of diseases they transmit to animals and humans. Damage resulting from direct tick feeding activities and the cost of controlling the pathogens they transmit to libestock accounts for the lagest source of economic losses in the livestock industry. Currently the only widely available practical method to control ticks is the use of chemical acaricides. This approach is associated with serious limitations such as environmental and food chain contamination by acaricides. These limitations 
and the growing community awareness regarding the harmful effects of acaricides have stimulated research into alternative tick control methods. Among the several alternative tick control methods that have been considered, immunological protection of hosts against tick infestation is practical and sustainable. Findings from a series of studies by an Australian group leading to commercialization of a first ever anti-arthropod vaccine, e. g., TickGARD and Gavac, provided practical evidence on the use of an immunological approach to control ticks. However the success of this approach is dependent upon identification of key tick molecules that are involved in the mediation of key physiological roles for use as candidate vaccine antigens. From this stadpoint, we made here the brief introduction about our recent achievements on the identification and characterization of several candidate molecules, namely phenoloxidse, serineprotease, peroxiredoxin and troponin, from several tick species.

\title{
S-IV-3) SIMIAN MALARIA PARASITES AS ZOONOTIC PATHOGENS
}

\author{
SATORU KAWAI ${ }^{1}$, OHTA NOBUO ${ }^{2}$, MATSUDA HAJIME ${ }^{1}$
}
Deparment of Tropical Medicine \& Parasitology, Dokkyo University School of Medicine ${ }^{1}$, Department of Mesical Zoology, Nagoya City University Medical School ${ }^{2}$

The parasites of genus Plasmodium have a wide range of vertebrate hosts. Although they are generally known to have strict host specificity, some simian malaria parasites are infective to human beings, causing zoonotic infectious diseases. Here we describe simian malaria parasites zoonotic pathogens.

To date, about 25 spices of simian maralia parasites have been reported. These occur in New World monkeys, Old World monkeys, gibbons, great apes, and lemurs. Plasmodium of the primate hosts are classified into five groups according to Giemsa-stained feature of stages found in the peripheral blood and the periodicity of their erythrocytic schizogony: falciparum type, vivax type, maraliae type, ovale type and other type. At least six species of simian malaria parasites (P. brazilianum, $P$. cynomolgi, $P$. inui, $P$. knowlesi, $P$. schwetzi and $P$. simium) are known to infect humans either naturally or experimentally including accidental laboratory infections.

Generally, the clinical course of infection with simian malaria parasites in humans is mild with low parasitemia, and chemotherapy, where necessary, has been effective. Although human malaria infections acquired from non-human primates are rare, an accurate diagnosis should be made in any suspected cases. Diagnosis is based on the detection of parasites in stained thin blood smears but these must be interpreted with great caution because simian malaria parasites are virtually indistinguishable from the erythrocytic stages of human malaria parasites.

Some epidemiological studies on simian malaria have pointed out the possible role of malaria infected monkeys as natural reservoirs for infection in humans. $P$. brazilianum is widely distributed in several species of monkeys in Central and South America. This malariae type species is morphologically and molecularly similar to human parasite $P$. malariae, thus they are virtually identical and should probably be considered to be a single malaria species. In fact, serological studies in the Amazon Basin have shown the prevalence for anti-P. brazilianum /P. malariae antibodies to be high both in monleys and in local Indian tribes, suggesting that this from of malaria is authentic zoonosis in that region. These findings indicate the possibility that monkeys living in the rainforest of Amazon area are natural reservoirs for both simian and human malaria. 


\title{
S-IV -4) LEISHIMANIASIS AS A ZOONOSIS: DNA DIAGNOSIS AND MOLECULAR EPIDEMILOGY BASED ON PCR AMPLIFICATION AND CHARACTERISTICS OF THE LEISHMANIA MINI-EXON GENE
}

\author{
KEN KATAKURA \\ Department of Parasitology, Gunma University School of Medicine
}

Leishmaniasis is typical vector-borne and zoonotic disease. The disease is transmitted by the sandfly and more than 100 vertebrates are known as resevoir hosts. To control leishmaniasis most effectively, an accurate diagnosis of patients well as epidemiological studies on reservoir animals and sandfly vectors are required. For DNA diagnosis of leishmaniasis, we have developed a PCR method based on amplification of the Leishmania mini-exon gene. The mini-exon gene is tandem repeated as many as 100-200 copies on the parasite genome and the spacer region is defferent in length and in sequence among different Leishmania species. We evaluated the usefulness of this PCR method in two endemic countries, China and Ecuador.

In Xinjiang-Uigur Autonomous Region in China, there have been sporadic cases of visceral leishmaniasis. We obtained positive PCR products corresponding to $L$. donovani complex in bone marrow or buffy coat samples in 11 out of 13 serologically positive kala-azar patient. However, none of buffy coat samples from nine patients with antimony were all PCR-negative. DNA samples from buffy coats of 17 domestic in the endemic area were also PCR-negative.
In addition, we identified parasite isolates from great gerbils (Rhombomys opimus) and sand flies (Rhlebotomus mongolensis and P. andrejevi) as L. turanica or L. gerbilli by DNA sequencing of the PCR-amplified mini-exon genes.

In Ecuador, amplification of the mini-exon gene specific to L. braziliensis complex was detected in the skin biopsy sampls from patients with cutaneous leishmaniasis, indicating the usefulness of PCR amplification of the gene for diagnosis of cutaneous leishmaniasis. Chromosomal locations of the mini-exon gene were different among L. panamensis isolates, futher indicating the DNA karyotype variation among parasites in the endemic region. Furthermore, DNA sequencing of amplified mini-exon genes of isolates from a sloth (Choloepus hoffmanni), a squirrel (Sciurus vulgaris) and sand flies (Lutzomyia hartomani) revealed the presence of Endotrypanum monterogeii and E. schaudinni in Ecuador. Since some of these isolates were reported as $L$. equatorensis in the previous paper, it is impottant for the differentiation between Leishmania and Endotrypanum for epidemiological studies on leishmaniasis.

\section{S-V - 1) PROGRESS OF GLOBAL POLIO ERADICATION PROGRAMME}

\section{TATSUO MIYAMURA}

Department of Virology II, National Institute of Infectious Diseases

The global polio eradication programme has launched by world health oraganization in 1988 . The main strategy is (i) detecting patients with acute flaccid paralysis (AFP) and (ii) confirming real polio cases both by clinical and virological examination. If the number of AFP patients due to wild type-polioviruses becomes zero and if the situation is maintained for a certain period of time ( $\sim 3$ years), the programme is accomplished. In practice, the programme consists of extensive vaccination and highy effective surveillance. Since the key element is oral attenuated vaccine, this programme is considered to be, in other words, an experiment to replace wild polioviruses with vaccine strains in global level.
In the American Region, the programme was accomplished in 1991 and no AFP patients due to wild polioviruses have been reported in spite of extensive vaccination and surveillance. In our Western Pacific Region, the last polio case was found in Cambodia in March 1997, and since then no genuine polio cases by wild polioviruses have been reported. The certification committee declared in October 2000 that transmission of wild polioviruses has completely interrupted and now the region is wild polio-free. In the European region, the last polio case is considered to be the one in Turkey in 1998.

The initial target of the WHO programme was 2000. Although the accomplishments are delayed than expected, 
the programme is now at the very final stage. However at the very end, the following problems became clear; (i) the areas where wild polio viruses still exist are the areas with serious internal war and international collaborative efforts are generally difficult to access (Afghanistan, Somalia, Angola, etc $\cdots$ ), (ii) polio-free declaration in the regional level sometimes induce negative effects for the maintaining the high level of vaccination and sustaining good surveillance.
The latter is particularly important because in some areas where wild polioviruses are no more detected, vaccine derived poliovirus caused poliomyelitis outbreak in low or non-immunized population. The eradication of poliomyelitis does not automatically mean the abolishment of vaccination. It is the time to consider how we can stop polio vaccination (polio end game).

\title{
S-V-2) INTERNATIONAL COOPERATION IN THE AREA OF TUBERCULOSIS CONTROL
}

\author{
NOBUKATSU ISHIKAWA
}

The Research Institure of Tuberculosis, JATA, Tokyo

Global burden of Tuberculosis and DOTS:

Tuberculosis is now a global burden as one third of the global population has been infected by M.tuberculosis, causing 8 million new cases and 2 million deaths every year, WHO has developde a global strategy called DOTS through the analysis of the success stories in the world. DOTS consists of the following 5 components; government commitment, microscopic examination for diagnosis to the symptomatics, safe and regular supply of TB drugs, direcr observation of medication with short course regimen, routine monitoring with recording and reporting system. DOTS has yet covered only half the global population and one third of the estimated number of patients, The international cooperation must be therefore strengthened to accelerate global expansion of DOTS.

International Cooperation for TB Control by Japan:

Japan has a long history of international cooperation in the area of TB control since early 1960s both through the government and NGOs. International training courses held at research Institute of Tuberculosis since 1963 have had a global reputation wit more than 1500 participants from 80 contries. New challenges are; donation of drugs which are needed for DOTS expansion, recruit of the local staff for the project, or support for the nation-wide expansion of the program. Flexible approaches are needed according to the needs and effects. Coordination with other and international agencies such as WHO, or NGOs should be actively made, and global commitment both technical and political need to be strengthened.

Support System and Base Establishment inside Japan:

The base capacity inside Japan should be further strengthened, for manpower development for international works, overseas project support, or collaborative research.

\section{S-V-3) MALARIA CONTROL PROGRAM IN LAO PDR SUPPORTED BY JAPANESE GRANT AID FOR CHILD HEALTH}

\author{
JUN KOBAYASHI ${ }^{1,3}$, SAMLANE PHOMPIDA ${ }^{2}$, ATARU TUZUKI ${ }^{1}$, TAKAYAKI SAITO ${ }^{1}$, and YOSHIYA SATO ${ }^{3}$ \\ Japan International Cooperation Agency (JICA) Laos Office', \\ Center of Malariology, Parasitology and Entomology (CMPE), Ministry of Health, Lao PDR ${ }^{2}$, \\ Department of Parasitology, University of the Ryukyus ${ }^{3}$
}

In Lao PDR, Malaria control program using Impregnated Bed Net (IBN) stated from 1998 in nation wide according to Roll Back Malaria Initiative. Project in three central provinces was supported by Japanese Grant Aid for Child Health under the supervision from CMPE, Ministry of Health and JICA expert. Total of 40000 bed nets and Insecticide (Deltamethrin) were donated to CMPE and three provincial health offices in the beginning of 1999. Until end of 2000 , it was reported that $81 \%$ of bed bet was delivered to the communities. Commune (Sub-district consisted 
by $5-10$ villages) was applied as unit to deliver bed net costeffectively. One village was selected to hold Training of Trainer (TOT) in each commune to expand to other villages by district malaria staffs, village leaders or health workers without support from central level. Total expense to deliver the bed net using these systems was approximately only US $\$ 10000$.

Total number of malaria patients and slide positive rate of malaria (SPR) in all public health facilities decreased markedly in 2000. In the pilot district; Bourapha district in Khammoaune province, it was suspected that IBN program was well operated according to the analysis the report from district health office. The report showed $100 \%$ coverage to villages and 3.81 person per IBN as mean coverage in the community. After operation IBN program, KAP study was carried out to evaluate the program in all communes in pilot district. High percentage of household where bed net wasn't set was presented in the remote area. Moreover, low malaria knowledge was confirmed among inhabitants who live in household without bed net. It was suggested that strengthening of IEC activities is necessary in especially remote area and poor families. Thus, the new approach to the inhabitants was applied to sustain the project. To strengthen the community participation, group discussion and mass diagnosis using rapid diagnosis method were conducted before ordinary health education using video or poster. The efficacy of these trials will be evaluated in beginning of 2002.

It is expected that improvement of cost recovering system and application of social marketing system support to sustain the project with strengthening IEC activities.

\title{
S-V-4) LEISHMANIASIS: ITS RECENT TOPICS AND RESEARCH ACTVITIES IN ECUADOR
}

\section{YOSHIHISA HASHIGUCHI}

\author{
Department of Parasitology, Kochi Medical School, Nankoku, Kochi Japan
}

Leishmaniasis is one of the eight target diseases of the Improved Control of TDR diseases (WHO, 2000). The diseases are endemic in 88 countries on the five continents, with a total of 35 million people at risk, and the diseases afflict at least 12 million people worldwide; the numbers are however probably underestimated; figures of 2 million new cases per year, including 1.5 million cases of cutaneous leishmaniasis (CL) and 500,000 of visceral leishmanisis (VL) are likely (Desjeux, 2001). In this symposium, the following points are mentioned as recent topics in leishmaniasis research. 1) Epidemiological changes due to Leishmania/HIV co-infection. Such cases are increasing yearly and the co-infection is prevalent in 33 countries, including non-endemic areas, such as Germany, Switzerland, United Kingdom, Belgium, Denmark and etc. In the coinfection areas, transmission cycles are also changing from zoonotic endemics to anthroponotic epidemics; person to person direct trasnsmissions by syringe in drug users are found, especially in south-western Eurpe. 2) Vaccine trials. Recent vaccine trials performed for CL in Iran and for VL in Sudan, and for CL in Brazil, Ecuador and Colombia were briefly reviewed, including immunotherapy done in Venezuela. 3) Chemotherapy for leishmaniasis. Available therapy for the disease was reviewed and special emphasis was given to the trials with miltefosine as oral drug for VL used especially in India. Besides, leishmaniasis research project carried out during about 18 years from 1982 to 2001 was retrospectively evaluated, mainly emphasizing on the following points: 1) characterization and determination of Leishmania spp., vector sandflies, and reservoirs at each endemic areas of Ecuador; 2) therapy trials using paromomycin ointment and Glucantime lotions as local treatment and Mephaquin and artesunate as oral treatment; 3) detection of epidemiological characteristics of each area and etc.; 4) development of material collections in the field condition for molecular diagnostic tools. 


\title{
S-V-5) CURRENT ACTIVITIES OF REGIONAL NETWORK ON SCHISTOSOMIASIS CONTROL IN ASIA AND ROLES OF THE JAPANESE RESEARCHERS IN THE NETWORK
}

\author{
NOBUO OHTA \\ Department of Medical Zoology, Nagoya City University Medical School, Nagoya, Japan.
}

Asian schistosomiasis, schistosomiasis japonica, is endemic in east-Asian countries especially in China and the Philippines. In comparison with other human schistosomiasis, the disease control is difficult because of the presence of reservoir hosts and also environmental factors. Under the support of WHO, a regional network for controlling Asian schistosomiasis (RNAS) was established as international cooperation activities including the two endemic countries as well as other countries such as Japan and Australia, in which research on schistosomiasis has been accumulated. Endemic situation is different between China and the Philippines, therefore, control strategies are different between the two countries. In the previous joint RNAS meetings, methods for epidemiological evaluation, developing new diagnostic tools, and vaccine development were the common interest. Japanese researchers are requested to join the cooperative activities in such fields.

Endemic situation of schistosomiasis japonica in both two countries at a turning point, because WHO gave relatively intense supports for the disease control in the past decades. Situation has been much improved, however, support by WHO was already over by the end of 2000 . In
China, the number of endemic Prefectures and the number of advanced cases showed significant reduction, and betterorganized countermeasures are needed. For example, selected chemotherapy is the choice in many places in China, however, such program management is now not easy because of financial problem. Reduced endemicity means difficult step for disease eradication and needs much more budget and human resources. The same situation is also in the Philippines. Along with social development, endemicity is deeply affected by some artificial conditions. The threegauge dome in China is the case, Epidemiological suevey in Human, Hubei, Sichuan and Jiangxi Provinces are underway.

Cost-effective countermeasure is the most important subject this region. Technical and scientific assistance from Japan will be good contribution. In line with such situation, Japanese researchers are joining partnership for vaccine development, and for developing new epidemilogical evaluation. RNAS activity has just started, and should be expanded though the partnership in east-Asian countries. This is, in turn, a good opportunity for Japanese reseachers, since schistosomiasis is still attractive field of research. 


\title{
A-1) CHANGING PATTERNS OF ANTIMALARIAL DRUG RESISTANCE IN PLASMODIUM FALCIPARUM MIRROR THE CHANGE OF THE NATIONAL MALARIA TREATMENT POLICY IN MALAWI
}

\author{
B. BWIJO ${ }^{1}$, A. KANEKO ${ }^{1}$, T. TSUKAHARA ${ }^{1}$, M. TAKECHI ${ }^{1,2}$, I. L. ZUNGU ${ }^{3}$ Y. MORIYAMA ${ }^{4}$, \\ J. K. LUM ${ }^{1}$ AND T. KOBAYAKAWA ${ }^{1}$.
}

\begin{abstract}
Department of International Affairs and Tropical Medicine, Tokyo women's Medical University, Tokyo, Japan',
Yachiyo Hospital Hiroshima, Japan ${ }^{2}$,

Community Health Sciences Unit, Ministry of Health and Population, Lilongwe, Malawi Faculty of Tropical Medicine, Mahidol University, Bangkok, Thailand ${ }^{4}$.
\end{abstract}

In Malawi chloroquine was replaced by sulfadoxine/ pyrimethamine (SP) in 1993 because of increasing chloroquine failures of Plasmodium falciparum cases. Seven years after the change in malaria treatment policy, we evaluated the sensitivity of $P$. falciparum to different antimalarial drugs both in vivo and in vitro in asymptomatic children and adults in Salima District, Malawi.

A total of 504 individuals were examined for parasitaemias. Of them, $78 \%$ were infected with malaria. Monoinfections of $P$. falciparum and $P$. malariae accounted for $97 \%$ and $1 \%$ of the positives respectively, while $2 \%$ had mixed infections. Children $<6$ years were mostly infected (93\%) and had high parasite rate and spleen rate.

Of 173 subjects selected for in vivo trials, 61 were treated with chloroquine, 46 with SP, and 66 with Malarone (atovaquone/proguanil) and were followed for 28 days. The in vivo sensitivity response of the three drugs tested was not significantly different $(78-88 \%, \mathrm{p}>0.05)$, however, Malarone group showed a significantly higher proportion of RIII/ RII resistance than chloroquine and SP groups (9\% vs. $2 \%$, $\mathrm{p}<0.02)$.

The in vitro sensitivity of $104 P$. falciparum isolates, to chloroquine, SP, pyrimethamine, amodiaquine, quinine, and mefloquine was also assessed using WHO test kits. Ninety eight percent of the parasites failed to mature at the lowest concentration of chloroquine $(0.2 \mu \mathrm{mol} / l \mathrm{BMM})$ precluding $\mathrm{EC}_{50}$ and $\mathrm{EC}_{90}$ estimates. Although $44 \%$ of the isolates showed schizont maturation at the highest concentration of pyrimethamine, $83 \%$ were inhibited at the cut-off concentration of SP combination.

Our study in Malawi shows the recovery of chloroquine sensitivity by comparing both in vivo and in vitro tests of the same $P$. falciparum isolates. The combination of sulfadoxine and pyrimethamine was effective in the presence of pyrimethamine-resistance isolates, indicating the advantage of drug combinations as opposed to single drug therapy in clinical practice. Thus, if chloroquine is removed for a sufficient period of time, it might be effectively used once again in combination with other drugs to treat malaria in Sub-Saharan Africa.

\section{A-2) ANALYSIS OF PFMDRI GENE IN MEFLOQUINE RESISTANT PLASMODIUM FALCIPARUM}

\author{
KHURSHIDA BEGUM ${ }^{1}$, HYE-SOOK KIM ${ }^{1}$, YOHEI OKUDA ${ }^{1}$, YUSUKE WATAYA ${ }^{1}$ \\ MIKIO KIMURA ${ }^{2}$ AND TAKAHISA HURUTA ${ }^{3}$
}

\author{
Faculty of Pharmaceutical Sciences, Okayama University, Tsushima, Okayama 700-8530, Japan ${ }^{1}$, \\ National Institute of Infectious Diseases, Toyama 1-23-1, Shinjuku-ku, Tokyo 162-8640, Japan² \\ and The Institute of Medical Science, The University of Tokyo, 4-6-1 Shirokanedai, Minato-ku, Tokyo 108-8639, Japan ${ }^{3}$
}

Objective: Drug resistance is a major problem for the treatment of malaria. Therefore new antimalarials are necessary to combat resistant parasites. Mefloquine is an important drug, but resistant parasite are also appeared and now increasing. Our objective was to analyze the mechanism of mefloquine-resistant of Plasmodium falciparum parasite to develop new drugs.
Methods: A mefloquine-resistant strain Plasmodium falciparum 523a (isolated from mefloquine-resistant patient) was continuously cultured under progressively increased mefloquine pressure. After two years, we got resistant parasite (designated as 523a $\mathrm{R}$ strain) and now can able to grow at $2.5 \times 10^{-7} \mathrm{M}$ mefloquine concentration. The original strain was cultured without drug under the same condition 
considered as control (523a S strain). The sensitivity to other antimalarials against these strains (523a S and 523a R) have also been performed. The amino acid residues at 86, 1034, 1042 and 1246 positions of pfmdr1 gene in chromosome 5 of $P$. falciparum (523a S and 523a R) were analyzed using Dye Terminator method followed by particular domain amplified by PCR and compared with previously reported amino acid residues which thought to involved mefloquine resistance. The size of chromosome 5 has been measured. We performed cloning from resistant strain and determined the sensitivity to other antimalarials against clone/24.

Results and Discussion: It is found that, there is no difference in amino acid sequence between mefloquine sensitive (523a S) and mefloquine resistant (523a R) strain, although resistant strain showed about 39 times higher $\mathrm{IC}_{50}$ value than sensitive strain. Moreover, 523a R strain showed decreased sensitivity to artemisinin and halofantrine and in- creased sensitivity to chloroquine. The overexpression of pfmdrl mRNA has been observed and it is about 7.2 times higher than sensitive strain. Our Pulsed Field Gel Electrophoresis result revealed chromosome 5 contained a mixed population of sensitive and resistant parasites. To get more resistant parasites we performed cloning. Clone/24, the highest resistant clone showed similar results as 523a $\mathrm{R}$ strain to other antimalarials, increased sensitivity to chloroquine and decreased sensitivity to artemisininin and halofantrine.

Our results may explain amino acid sequence should not related to drug resistance and sequence polymorphism of $p f m d r l$ gene. As overexpression of gene $p f m d r l$ found about 7.2 times higher than sensitive strain, it is likely that overexpression of pfmdrl gene may be associated in mefloquine resistance mechanism. Now we are measuring the size of chromosome 5, overexpression of mRNA and gene analysis of $p f m d r l$ against clone/24.

\title{
A-3) RECOVERY OF CHLOROQUINE SENSITIVITY AND LOW PREVALENCE OF K76T IN PFCRT AFTER THE CHANGE OF MALARIA TREATMENT POLICY IN MALAWI
}

\author{
TOSHIHIRO MITA', AKIRA KANEKO르, BWIJO BWIJO', TAKAHIRO TSUKAHARA', YOSHINARI MORIYAMA ${ }^{1}$, \\ MIHO TAKECHI ${ }^{2}$, J. KOJI LUM ${ }^{1}$, INNOCENT L. ZUNGU'², AND TAKATOSHI KOBAYAKAWA ${ }^{1}$
}

\author{
${ }^{1}$ Department of International Affairs and Tropical Medicine, Tokyo Women's Medical University School of Medicine, Tokyo, Japan \\ ${ }^{2}$ Community Health Sciences Unit, Ministry of Health and Population, Lilongwe, Malawi
}

In 1993 Malawi officially withdrew chloroquine as the first-line drug for the treatment of uncomplicated cases of malaria due to an increasingly high rate $(47 \%)$ of resistance. During field surveys conducted in 1998 and 2000 we investigated in vitro chloroquine resistance (CQR) and later assayed two genetic polymorphisms (K76T in pfcrt and N86 $\mathrm{Y}$ in $p f m d r l$ ) suggested to contribute to $\mathrm{CQR}$ in obtained Plasmodium falciparum isolates. Among 96 isolates exam- ined, only $9 \%$ showed CQR while $7 \%$ and $48 \%$ carried the $\mathrm{K} 76 \mathrm{~T}$ and N86Y mutations respectively. In contrast, the prevalence of K76T in other African countries with ongoing chloroquine use was $41-83 \%$. Thus, our findings suggest that the reduced drug pressure accompanying the change in national drug policy in Malawi has resulted in a significantly lower prevalence of the K76T mutation and consequently a substantial recovery of chloroquine sensitivity. 


\title{
A-4) DRUG RESISTANT MALARIA IN MINDANAO, THE PHILIPPINES-APPLICATION OF ANAEROPACK ${ }^{\circledR}$ MALARIA CULTURE SYSTEM TO IN VITRO DRUG SUSCEPTIBILITY TEST OF PLASMODIUM FALCIPARUM IN THE FIELD.
}

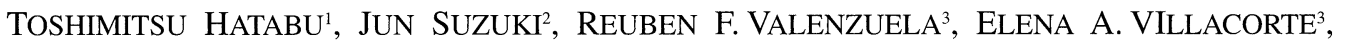 \\ PILARITA T. RIVERA ${ }^{3}$, SHIN-ICHIRO KAWAZU ${ }^{1}$, and SHIGEYUKI KANO ${ }^{1}$ \\ Research Institute International Medical Center of Japan, \\ The Tokyo Metropolitan Research Laboratory ${ }^{2}$, \\ and Department of Parasitology, College of Public Health, University of the Philippines Manila ${ }^{3}$
}

Since chloroquine-resisant Plasmodium falciparum was reported in 1960's, drug-resistance or decreased susceptibility for drugs of malaria parasites have expanded their distribution. Therefore, it is important to carry out the drug susceptibility in the field to obtain the epidemiological information against the drug-resistant malaria parasites in detail. However, it is different to isolate the fresh parasite or to examine the drug susceptibility for antimalarial drugs in the field because of the limited experimental conditions needed for the cultivation of the $P$. falciparum in vitro. In this report, drug susceptibility of $P$. falciparum isolates was determined using AnaeroPack ${ }^{\circledR}$ malaria culture system with portable thermostat in the field of Mindanao Island, the Philippines. Blood samples were obtained from 4 symptomatic Filipino patients with $P$. falciparum who admitted to the Davao regional hospital, in Tagum City. The aim of the study was clearly explained to all the patients and informed consent was obtained from them. Erythrocytes were resuspended in RPMI 1640 medium supplemented with $10 \%$ human serum. The culture plates including the blood samples were incubated at $37^{\circ} \mathrm{C}$ with portable thermostat. The 4 isolates were examined for the chloroquine-susceptibility by adding the drug to the cultured samples at serially diluted concentrations. After $36 \mathrm{hr}$ incubation, 2 isolates grew from ring form to schizonts. Then, a 100\% inhibitory concentration $\left(\mathrm{IC}_{100}\right)$ of one isolate was observed to be $1.28 \mu \mathrm{M}$ and that of the other isolate was $0.64 \mu \mathrm{M}$. Two other Isolates of 4 grew to trophozoite as late as after 48 hours' incubation and were also thought of as isolates of a certain degree of resistance. AnaeroPark ${ }^{\circledR}$ malaria culture system with portable thermostat was proved to be powerful and useful to conduct the drug susceptibility test in the field condition.

\section{A-5) AN EPIDEMIOLOGICAL STUDY ON MALARIA IN THE DISPLACED POPULATIONS IN VIET NAM}

\author{
SHIGEYUKI KANO ${ }^{1}$, SHUSUKE NAKAZAWA ${ }^{2}$ \\ Research Institute, International Medical Center of Japan', \\ and Institute of Tropical Medicine, Nagasaki University ${ }^{2}$
}

Malaria incidence is determined by a variety of factors, particularly the abundance of anopheline mosquitoes, the presence of malaria parasites, and human behavior. Reemergence of malaria is thus often associated with socioeconomic development and expanding infrastructure, population growth and urbanization. We report an example of malaria epidemics in the displaced populations in Viet Nam.

Study area was a newly colonized village called "Ben Tre-A New Economic Area" in Binh Phuoc province, which was located about a $100 \mathrm{~km}$ to the north of Ho Chi Minh City and quite near to Cambodia border. People had moved from the area called "Ben Tre" near the mouse of Mekong river and settled there. Seventy families including 203 peo- ple were residing in the area and just started to cultivate the land growing rubber trees, nuts, pepper and rice for their support. Access to the village was not easy by walking but only feasible by a small motor bike. Electricity had not been supplied in the area.

We visited the place on the 13 June, 2001, with a microscope, and made thick blood films from 99 villagers who came to see us for free blood smearing for malaria. Five cases (12 y. o. male, 15 y. o. male, 42 y. o. female, 44 y. o. female, 65 y. o. female) showed positive slides out of the 99 , which was considered to be very high in number as could be obtained in a single day survey. They said they were sleeping in the mosquito nets, but that no spraying had been 
done in the area. They were taking no counter measures against mosquito bites when they were working in rubber woods in carly morning. The main vector in the area was reported to be Anopheles minimus.

The large-scale migration and resettlement of populations from malaria endemic areas into receptive areas were big problems in many parts of the world, however, on the contrary, a movement induced by rural impoverishment influenced by the over population from a non-endemic area to highly endemic areas will also affect the dynamics of the disease badly.

\title{
A-6) RECRUDESCENCE IN VITRO AFTER D-SORBITOL TREATMENT OVER NINE DAYS
}

\author{
SHUSUKE NAKAZAWA
}

Institute of tropical Medicine, Nagasaki University

Drug treatment of falciparum malaria is occasionally followed by a recrudescence. Recrudescences have been thought to occur due to drug resistant prasites or due to a low plasma concentration of drug. There have been several reports of discrepancy between in vivo and in vitro resistant tests. Recrudescent parasites obtained from patients were sensitive in the in vitro test. Those reports imply parasites survive drug treatment in some manner other than drug resistance.

Inactive parasites may escape from the effect of drug. More than $1.2 \times 10^{9}$ erythrocytes infected with cloned parasites were exposed to D-sorbitol treatment 12 hourly for nine days, then maintained in standard medium. D-sorbitol treatment destroys trophozoite and schizont infected erythrocytes and reduces parasite numbers to less than $1 / 500$ per one cycle (48 hours). Parasites reappeared from 4 to 6 weeks after the treatment and multiplied. Erythrocytes infected with recrudescent parasites were as vulnerable to Dsorbitol treatment as those were before recrudescence experiments.

As D-sorbitol treatment causes 500-fold reduction in parasite numbers per cycle, parasite numbers are presumed to be decreased to less than $1 / 500^{4.5}\left(=1.4 \times 10^{-12}\right)$ for nine days. This reduction is far beyond the initial parasite number. Ring-form infected erythrocytes are resistant to the treatment. The results suggest that small percentage of parasites may remain at ring-form stage, so that they survive the treatment. And after treatment they are activated and lead to an observable infection.

\section{A-7) CHARACTERISTICS OF CHOLERA TOXIN-PRODUCING VIBRIO CHOLERAE STRAINS ISOLATED FROM SEAFOOD IN MALAYSIA}

\author{
CHIEN-HSIEN CHEN ${ }^{1}$, TOSHIO SHIMADA², NASRELdIN E. HUSSEIN ${ }^{3}$, \\ SON RADU ${ }^{3}$, AND MITSUAKI NISHIBUCHI ${ }^{4}$ \\ Graduate School of Medicine, Kyoto University ${ }^{1}$, \\ School of Health Science, Tokyo Medical and Dental University ${ }^{2}$, \\ Department of Biotechnology, Faculty of Food Science and Biotechnology, University Putra Malaysia ${ }^{3}$, \\ Center for Southeast Asian Studies, Kyoto University ${ }^{4}$
}

International spread of enteric infections is becoming a very important issue since the movement of humans and foods across the international borders is increasing year by year. It is known that cholera is endemic in the Bengal area, but cholera outbreaks have been reported in the surrounding areas. We have been studying whether the causative agent of cholera is widely distributed in the environment of such areas surrounding the Bengal area. Vibrio cholerae 0139 emerged in the Bengal area in 1992 and caused a big outbreak. We previously isolated cholera toxin-producing strains of O139 serotype from the seawater in Malaysia. We therefore examined the seafoods retailed in this country in this study. We purchased and examined the fresh seafoods at 10 sampling sites between 1998 and 1999. As the result, 
20 strains of $V$. cholerae carrying the $c t x$ gene were isolated from shrimps, squids, crabs, and shellfish. They belonged to serotypes O1 Ogawa (one strain), O139 (14 strains), and $\mathrm{R}$ (rough, but their $r f b$ genes being of the $\mathrm{O} 1$ type, 5 strains). All the $c t x$-positive strains produced cholera toxin in vitro and possessed the tcpA gene of El Tor type. The $c t x$-positive strains of $\mathrm{O} 1$ and $\mathrm{O} 139$ serotypes had TLC (toxin-linked cryptic) element, but those of R serotype did not. The R-serotype strains were similar to the clinical O1 Ogawa strain isolated in Kelantan in 1999 because they were negative for the TLC element and shared the same antibiogram. We previously found similar clinical strains in southern Thailand up until March 1998. We compared the environmental strains by various DNA fingerprinting techniques along with the clinical strains isolated in India, Bangladesh, and Malaysia. The pulsed-field gel electrophoresis method gave the highest resolution and the results indicated that environmental O139 strains may have been introduced from India in 1993 and persisted in Malaysian environment since then and that environmental strains of $\mathrm{O} 1$ and $\mathrm{R}$ serotypes may have served as the source of cholera in Malaysia.

\title{
A-8) FLAGELLA FILAMENT PROTEIN (FliC) INDUCES HUMAN $\beta$-DEFENSIN-2 (hBD-2) PRODUCTION IN HOST CELLS
}

\author{
AKIHIRO WADA, KEN-ICHI OGUSHI, AND TOSHIYA HIRAYAMA
}

Department of Bacteriology, Institute of Tropical Medicine, Nagasaki University.

Antimicrobial peptides such as human $\beta$-defensins are crucial for host defense at mucosal surfaces. Expression of defensin genes is regulated in response to infection and inflammation. To evaluate the role of defensin in S. enteritidis infection, bacterial factors responsible for induction of human $\beta$-defensin-2 (hBD-2) mRNA expression in Caco-2 human carcinoma cells were determined. Salmonella enteritidis supernatants of these strains induced hBD-2 mRNA expression in Caco-2 human carcinoma cells. The supernatant factor was heat-stable and proteinase-sensitive. Using luciferase as a reporter gene for a $\sim 2.1 \mathrm{~kb} h B D-2$ promoter, the hBD-2-inducing factor in culture supernatant of $S$. enteritidis was isolated. After purification by anion exchange and gel-filtration chromatography, the hBD-2-inducing factor was identified as a 53-kDa monomeric protein with the amino-terminal sequence, AQVINTNSLSLLTQNNLNK, which is identical to that of the flagella filament structural protein (FliC) of S. enteritidis . Consistent with this finding, the $53-\mathrm{kDa}$ protein reacted with anti-FliC antibody, which prevented its induction of hBD-2 mRNA in Caco- 2 cells. In agreement, the hBD-2-inducing activity in culture supernatant was completely neutralized by anti-FliC antibody and the lysate with recombinant FliC but not control lysate has $\mathrm{hBD}$-2-inducing activity in culture supernatant.

FliC did not enhance luciferase activity in Caco- 2 cells transfected with control luciferse-reporter plasmid (pGL3), or hBD-2 reporter plasmids without NF- $\kappa$ B site (pGL3-197 and pGL3-938mt), consistent with involvement of NF- $\mathrm{kB}$ in the induction of hBD-2 by FliC. In gel retardation analyses, FliC increased binding of NF- $\mathrm{KB}$ (p65 homo dimer) to hBD-2 gene promoter sequences. These data show that $\mathrm{S}$. enteritidis FliC induces hBD-2 expression in Caco- 2 cells via NF- $\kappa \mathrm{B}$ activation, and thus plays an important role in upregulation of the innate immune response. 


\title{
A-9) ENHANCED EXCYSTATION AND METACYSTIC DEVELOPMENT OF ENTAMOEBA INVADENS BY CYTOCHALASIN D
}

\author{
ASAO MAKIOKA ${ }^{1}$, MASAHIRO KUMAGAI $^{1}$, HIROSHI OHTOMO ${ }^{1}$, SEIKI KOBAYASHI ${ }^{2}$ AND TSUTOMU TAKEUCHI ${ }^{2}$
}

\author{
Department of Tropical Medicine, Jikei University School of Medicine ${ }^{1}$, \\ Department of Tropical Medicine and Parasitology, Keio University School of Medicine ${ }^{2}$
}

\begin{abstract}
Excystation and metacystic development are the process by which Entamoeba initiates infection. Although the process was described previously, little is known about the mechanism involved. The process of excystation and metacystic development includes movement of the protoplasm of cysts, separation it from the cyst wall, escape of the entire protoplasmic contents through a minute perforation in the cyst wall, and finally production of 8 trophic amoebae. There is, however, no study on the relation of the actin filaments to the excystation and metacystic development of Entamoeba. Therefore, we examined the effect of three actinmodifying drugs, cytochalasin D, latrunculin A, and jasplakinolide, on the excystation and metacystic development of E. invadens by transfering the cysts to growth medium with the drugs. Cytochalasin D unexpectedly increased the number of metacystic amoebae of E. invadens during incu-
\end{abstract}

bation. Metacystic development, which was determined by the number of nuclei of metacystic amoebae, was faster in the culture with cytochalasin $\mathrm{D}$ than without the drug. These results suggest that cytochalasin D enhances the excystation and metacystic development. In contrast, latrunculin A and jasplakinolide inhibited these process. No excystation occurred in encystation medium even in the presence of cytochalasin D, suggesting that growth medium is essential for excystation. Excystation was further enhanced when the cysts were incubated with cytochalasin $\mathrm{D}$ before culture in growth medium with the drug. The enhancing effect of cytochalasin D on the excystation and metacystic development was abrogated by jasplakinolide. Thus the results indicate that cytochalasin $\mathrm{D}$, unlike latrunculin $\mathrm{A}$ and jasplakinolide, caused enhancement of the excystation and metacystic development of this parasite.

\section{A-10) INVOLVEMENT OF SIGNALING MOLECULES IN THE GROWTH AND ENCYSTATION OF ENTAMOEBA INVADENS}

\author{
ASAO MAKIOKA ${ }^{1}$, MASAHIRO KUMAGAI ${ }^{1}$, HIROSHI OHTOMO', \\ SEIKI KOBAYASHI ${ }^{2}$ AND TSUTOMU TAKEUCHI ${ }^{2}$ \\ Department of Tropical Madicine, Jikei University School of Medicine', \\ Department of Tropical Medicine and Parasitology, Keio University School of Medicine ${ }^{2}$
}

Signaling molecules are responsible for numerous cellular responces including cell proliferation and defferentiation. There are, however, no studies on signaling for the growth and encystation of Entamoeba. Therefore, we determined whether signaling through protein kinase C (PKC), mitogen-activated protein kinase (MAPK), and phosphatidylinositol 3-kinase (Pl 3-kinase) is involved in the growth and encystation of $E$. invadens by using several inhibitors of these enzymes. Among four inhibitors (staurosporine, chelerythrine hydrochloride, calphostin $\mathrm{C}$, and D-erythrosphingosine) of PKC used, the former two inhibitied the growth and encystation of E. invadens. As staurosporine is a potent but not selective inhibitor of PKC, chelerythrine was used for further experiments. Addition of chelerythrine after induction of encystation was also effective for inhibi- tion of encystation. The chelerythrine effect on trophozoites in encystation medium was irreversible, whereas it was reversible in growth medium. All MAPK and MAPKK inhibitors including SB203580, apigenin,forskolin, olomoucine, prostaglandin E2, hypericin, and PD98059 had no effects on the growth and encystation of this parasite. Wortmannin, a specific inhibitor of Pl 3-kinase, also inhibited the encystation of E. invadens. Addition of wortmannin after induction of encystation reduced the number of cysts formed. Like chelerythrine, the wortmannin effect on trophozoites in encystation medium was irreversible. These results are the first evidence for participation of $\mathrm{PKC}$ and $\mathrm{Pl}$ 3-kinase in the growth and encystation of E. invadens, contributing to further understanding of Entamoeba growth and encystation and their inhibition. 


\title{
A-11) BACTERIAL EXPRESSION OF A HUMAN MONOCLONAL ANTIBODY-ALKALINE PHOSPHATASE CONJUGATE SPECIFIC FOR ENTAMOEBA HISTOLYTICA
}

\author{
HiROSHI TACHIBANA ${ }^{1}$, YUTA NAKATA ${ }^{1}$, XUN-JiA CHENG ${ }^{1}$, \\ YOSHIMASA KANEDA ${ }^{1}$ AND MASATAKA TAKEKOSHI ${ }^{2}$
}

Departments of Infectious Diseases ${ }^{1}$ and Molecular Life sciences ${ }^{2}$, Tokai University School of Medicine

We previously produced human monoclonal antibody Fab fragments specific for Entamoeba histolytica in Escherichia coli. For application of these Fab fragments for diagnostic purposes, an experssion vector to produce a fusion protein of Fab and alkaline phosphatase (PhoA) in $E$. coli was designed and constructed. E.coli PhoA gene was fused to the 3' terminus of the gene coding the heavy chain Fd region. As human antibody genes, the kappa and Ed genes from one of the previously prepared antibody clones, $\mathrm{CP}-33$, were used. The expressed fusion protein was purified by affinity chromatography using histidine-tag binding resin. Sodium dodecyl sulfate-polyacrylamide gel electrophoresis analysis of the protein revealed two maior bands with apparent molecular masses of 25 and $75 \mathrm{kDa}$. To con- firm whether these bands represent the kappa chain and the fusion protein of Fd and PhoA, Western immunoblot analysis was performed. As expected, the $25-\mathrm{kDa}$ band was recognized by an anti-human kappa chain goat antibody, and the 75-kDa band was detected by an anti-PhoA rabbit antibody. When the fusion protein of CP33 and PhoA was incubated with formalin fixed trophozoites of $E$. histolytica and developed with substrate, the trophozoites were specifically stained. These results demonstrate that the bacterial expression of a human monoclonal antibody-PhoA conjugate specific for $E$. histolytica is possible and that the antibody can be used to detect $E$. histolytica antigen without the use of chemically conjugated secondary antibodies.

\section{A-12) THE REGULATORY ROLE OF NITRIC OXIDE (NO) IN PROLIFERATION OF TOXOPLASMA GONDII IN MOUSE BRAINS EXAMINED WITH THE TREATMENT OF L-NG-MONOMETHYL- ARGININE AND QC-PCR ASSAY METHOD}

\author{
Hye-SeOng Mun, Kazumi Norose, Fumie Aosai, Mei Chen, \\ HIDEKAZU HATA AND AKIHIKO YANO
}

Department of Infection and Host Dcfense, Gradualc School of Medicine, Chiba University

IFN- $\gamma$-activated macrophages have been demonstrated as important effector cells $T$. gondii infection via NOmediated killing mechanism. Previous studies demonstrated that the trealment with L-NG-monomethyl arginine (L-NMMA) of mice increased $T$. gondii numbers analyzed by using direct microscopy and immunofluorescence assay, although these estimation methods of $T$. gondii in tissues seem unreliable because $T$. gondii is an intracellular protozoan. In the present study, we examined the regulatory role of NO in proliferation of $T$. gondii by the use of our own established the quantitative competitive-polymerase chain reaction (QC-PCR) targeting SAG1 gene of $T$. gondii

$\mathrm{BALB} / \mathrm{c}$ and C57BL/6 mice were intraperitoneally (i. p. ) injected with PBS (as a control) or L-NMMA (175mg/ $\mathrm{kg}$ ), and the mice were i. p. infected with 200 or 400 cysts of $T$. gondii. All mice treated with L-NMMA died within 13 days post-infection. In contrast, $33 \%$ of the control
BALB/c and C57BL/6 mice treated with PBS and infected by 200 or 400 cysts of $T$. gondii died within 10 to 11 days post-infection and the remainder survived. These data showed that the treatment of L-NMMA reduced the host resistance of both susceptible C57BL/6 and resistant BALB/c mice to tigh dose infection of $T$. gondii. In an attempt to characterizc whether injection of L-NMMA results in enhancement of proliferation of $T$. gondii in brains of infected mice, the number of $T$. gondii in the brains was measured using QC-PCR targeting SAG1 gene 8 weeks after $T$. gondii infection. The number of $T$. gondii in the brains of L-NMMA-treated BALB/c and C57BL/6 mice was significantly higher than that in control mice. These data indicate that the treatment of L-NMMA increased the number of $T$. gondii in brains of BALB/c and C57BL/6 mice. After infection with $T$. gondii, peritoneal macrophages from PBS-treated BALB/c and C57BL/6 mice pro- 
duced high levels of NO. Peritoneal macrophages from LNMMA-treated BALB/c and C57BL/6 mice, however, produced low levels of NO. Thus, L-NMMA blocked NO synthesis of peritoneal macrophages of $T$. gondii-infected mice.
Activated macrophages of $T$. gondii-infected mice down-regulated proliferation of $T$. gondii in the brain and dissemination of $T$. gondii to the brains of infected mice via NO-dependent effector mechanisms.

\title{
A-13) T. GONDII INFECTION INDUCES ANTI-HSP70 AUTOANTIBODY IN A SUSCEPTIBLE C57BL/6 MICE BY MODULATING RAG GENES
}

\author{
Mei Chen, Fumie Aosai, Kazumi Norose, Hye-Seong Mun and AKihiko Yano \\ Department of Infection and Host Defense, Graduate School of medicine, Chiba University
}

Introduction: Toxoplasma gondii ( $T$. gondii) an obligate intracellular protozoan parasite, is an important cause of morbidity and mortality, especially in congenital toxoplasmosis and immunocompromised hosts. We have reported anti-T. $g$. HSP70 antibody as well as anti-mHSP70 autoantibody produced in dominantly $T$. gondii-infected C57BL/6 (B6; a susceptible strain) mice. The mechanism of autoantibody formation in $T$. gondii-infected mice is not well defined. The lymphoid-specific genes, recombinationactivating genes (RAGs) catalyze $\mathrm{V}(\mathrm{D}) \mathrm{J}$ recombination. The purpose of this study was to investigate the mechanisms of autoimmunity induced by $T$. gondii-infection.

Material and Methods: BALB/c and B6 mice were perorally infected with 5 cysts of Fukaya strain. Control uninfected and infected BALB/c and B6 mice were sacrificed on day 0, 3 and 7 after $T$. gondii-infection. Spleen, MLN, BM and PECs were collected for the determination of the expression of RAG gene. The $T$. gondii numbers in the tissues of uninfected and T. gondii-infected BALB/c and B6 mice were analyzed by quantitative competitive-PCR.

Results: The level of RAG1 mRNA expression significantly decreased in the spleen and MLN of B6 mice on day 3 and recovered and reached a plateau $1 \mathrm{wk}$ after $T$. gondii infec- tion. Before $T$. gondii infection, the expression of RAG1 was not observed in PECs of B6 mice. One week after $T$. gondii infection, RAG1 and RAG2 expression was induced in PECs of $T$. gondii-infected B6 mice. The level of RAG1 expression in BM of B6 mice gradually increased after $T$. gondii infection. These data indicated that the level of RAG1 expression was transiently down-regulated in the spleen and MLN 3 days after the infection, then a higher level of RAG1 expression was observed in the spleen, MLN, BM and PECs of B6 mice 7 days after $T$. gondii infection. Significant changes in the RAG1 expression in the spleen, MLN, BM and PECs of BALB/c mice was not shown after $T$. gondii infection. On the other hand, the numbers of $T$. gondii in the spleen and MLN of BALB/c and B6 mice reached a peak 7 days after the infection and then decreased. No $T$. gondii was detectable in BM and PECs in BALB/c mice throughout the course of infection.

Conclusion: Out data indicated that the expression of RAG was transiently down-regulated in the spleen and MLN but not in BM and PECs of $T$. gondii-infected a susceptible B6 mice and the levels of RAG expression correlated with the $T$. gondii numbers existent in the tissues.

\section{A-14) A THOUGHT EXPERIMENT ON THE LINK BETWEEN THE RISK OF CONGENITAL TOXOPLASMOSIS AND THE ANNUAL INFECTION RATES}

\author{
KOJI NAOI AND AKIHIKO YANO
}

Department of Infection and Host Defense, Chiba University Graduate School of Medicine

Toxoplasmosis, an infectious disease induced by Toxoplasma gondii ( $T$. gondii) an obligate intracellular protozoan, is commonly benigh or asymptomatic when acquired by healthy persons. However, it may give harmful effects to fetus when pregnant women contract a primary infection congenital toxoplasmosis (CT).

The risk of CT reflects the total number of women who acquire a primary infection in their pregnancy. Hence, 
it also correlates with that of women who acquire a primary infection in the gestational period: the age equal to or older than 15 years and younger than 45 years. In the present study, we made a theoretical analysis with a simple mathematical model on the total number of women in the gestational period who get a primary $T$. gondii infection, through which we found out the link between the risk of CT and the annual infection rates of $T$. gondii. Considering the differences in behavioral patterns, different annual infection rates, the rate before the gestational period (r1) and that after the period (r2), were applied to out model.

Our present study indicates, in the case that annual infection rate is constant $(\mathrm{r} 1=\mathrm{r} 2), 3.67 \%$ of annual infection rate maximizes the risk of $\mathrm{CT}$, while the rates vary if it is presumed that $\mathrm{r} 1$ is different from $\mathrm{r} 2$. Adding to it, changes in $\mathrm{r} 1$ would make a shift of the risk curve, while those in $\mathrm{r} 2$ would move the location on the same risk curve.

Based on our study, the risk of CT in Japan currently stands st a relatively lower level. However, the study implies that a possible epidemic of $T$. gondii infection could raise the risk steeply. From the standpoint of risk management, public intervention programs are required.

Our study also implies that public interventions for CT could generate different outcomes, depending on whether they target women before the gestational period or after the period. And a successful program in certain area could induce a harmful effect in another. Tailor-made medicine is required in public health policy as well as clinical medicine.

\title{
A-15) PHENOTYPE AND FUNCTION OF MURINE PERITONEAL CAVITY MACROPHAGE DERIVED DENDRITIC CELLS
}

\author{
MAKala LEVI, NishiKaWA YOSHIFUmi, KAMADA TAKENORI. XUAN XUENAN, \\ FUJISAKI KOZO, SUZUKI NAOYOSHI AND NAGASAWA HIDEYUKI
}

Natl Res Ctr for Protozoan Dis, Obihiro Univ of Agri Vet Med

We describe a two-step culture system using peritoneal macrophages from P30 (SAG-1) transgenic mice as a source of dendritic cell (DC) progenitors. The proliferative capacity of the progenitors was smplified in the first step of the culture (day 0-7) using a combination of early cytokines: interleukin 4 (IL-4); and granulocyte-macrophage colony-stimulating factor (GM-CSF). The second step of the culture started at day 7 with the removal of early growth factors to allow differentiation and final maturation of DC during 2 days of culture with interferon gamma (IFN- $\gamma$ ) plus Toxoplasma lysate antigen (TLA) as maturing agents. Here, we show that the resulting DC population exhibits typical dendritic cell morphology, expresses MHC class II and co-stimulatory molecules CD80 at higher levels, consistently synthesize IL-12, efficiently stimulate $\mathrm{T}$ cell responses in vitro using two way mixed lymphocyte reaction (MLR) and are able to present soluble antigen to $\mathrm{CD}^{+}$ spleen $\mathrm{T}$ cells.

\section{A-16) GROWTH INHIBITORY EFFECTS OF TRICLOSAN AGAINST BABESIA SPP. PARASITES}

\author{
SABINE BORK, NAOAKI YOKOYAMA, HIROSHI SUZUKI, HIDEYUKI NAGASAWA, KOZO FUJISAKI, \\ CHIHIRO SUGIMOTO AND IKUO IGARASHI
}

National Research Center for Protozoan Diseases, Obihiro Univ. of Agri. and vet. med.

The antimicrobial biocide triclosan | 5-chloro-2 (2.4dichlorophenoxy) phenol | has been reported recently to inhibit the growth of Plasmodium falciparum in vitro and $P$. berghei in mice (Nature Medicine, 7: 167-173, 2001). In the present study, we have evaluated the growth inhibitory effect of triclosan against the hemoprotozoan, ticktransmitted parasites, Babesia egui B. caballi and B. bovis
The growth inhibitory tests were carried out in vitro following the method of lgarashi et at. (Expt. Parasitol., 90: 290293, 1998). Different concentrations of triclosan were added to cultures containing an initial $1 \%$ parasitemia of Babesia parasites in 24-well plates and incubated at $37^{\circ} \mathrm{C}$. The medium was changed daily and the percent parasitemia was monitored on Giemsa-stained blood smears for five 
days. Parasite growth of $B$. egui and $B$. caballi was inhibited at drug concentrations of $20-200 \mu \mathrm{g} / \mathrm{m} l$, while growth inhibition of $B$. bovis was noted at $100-500 \mu \mathrm{g} / \mathrm{m} l$. Initial findings in in vitro studies are encouraging and suggest the use of triclosan as a potential drug against equine and bovine babesiosis. To further determine the efficacy of triclosan in vivo, we have started studies on its effect on Babesia rodhaini-and $B$. microti-infection in mice.

\title{
A-17) GEOPATHOLOGICAL STUDY ON MALIGNANT TUMORS IN WESTERN KENYA BETWEEN 1979 AND 1998
}

\author{
KAN TORIYAMA ${ }^{1}$, JANE WASIKE-SIMINYU ${ }^{2}$, MASACHIKA ISEKI ${ }^{1}$ AND MASACHIKA SENBA ${ }^{1}$ \\ ${ }^{1}$ Department of pathology, Institute of Tropical Medicine, Nagasaki University \\ ${ }^{2}$ Histology Section, Rift Valley Provincial General Hospital, Nakuru, Kenya
}

An ethnogeographic variation in the frequency of different types of tumors is mainly attributed to the interplay of varied causative factors such as exposure to ultraviolet light, chemical carcinogens, oncogenic viruses, genetic factors, and cultural practices among various populations. This study analyzed histopathologic specimens in western Kenya for 20 years during 1979 to 1998 with a focus on the following objectives; to examine ethnogeographic distribution and to relate the tumors to putative environmental causative factors. The most common malignant tumor was uterine cervix cancer, which is widely distributed in this area, fol- lowed by malignant lymphoma, including Burkitt's lymphoma, which is more prevalent among the Luo around the Lake Victoria, and squamous cell carcinoma of the skin among the Kalenjin in Tropical Highlands. In addition, several malignant tumors such as Burkitt's lymphoma, Kaposi's sarcoma, penile cancer, squamous cell carcinoma of the urinary bladder showed characteristic ethnogeographic distributions. These findings suggest that environmental factors, including oncogenic viruses, and cultural practices seem to play a main role in the development of malignant tumors in western Kenya.

\section{A-18) SYNERGISTIC EFFECT OF TWO SUSCEPTIBLE GENETIC MARKERS, HLA-B5*0101 AND IL-13P-A/A, ON THE DEVELOPMENT OF POST-SCHISTOSOMAL LIVER FIBROSIS}

\author{
KENJI HIRAYAMA ${ }^{1}$, MIHOKO KIKUCHI ${ }^{1}$, HONGGEN CHEN ${ }^{2}$, RATAWAN UBALEE ${ }^{1}$, \\ TONG YIN ${ }^{2}$, XIAONAN GU², JIANXIANG LIU ${ }^{3}$, SHAOJI ZHANG ${ }^{2}$, AND HONGCHANG YUAN \\ Department of Molecular immunogenetics, Institute of Tropical Medicine, Nagasaki University ${ }^{1}$, \\ Jiangxi Provincial Institute of Parasitic Disease ${ }^{2}$, \\ Department of Epidemiology, School of public Health, Shanghai Medical University ${ }^{3}$.
}

In 1995 , over 100,000 patients have been estimated to be infected with Schistosoma japonicum in Jiangxi province. One of the most serious complications is postschistosomal liver disease that develops within several years after the infection. Schistosomal egg antigen specific CD4+ $\mathrm{T}$ cells play a major role in the formation of granuloma through Th2 type cytokine production in experimental schistosomiasis mansoni. To identify the host genetic factors affecting the prognosis after infection, we have examined DNA polymorphism of 192 unrelated past patients who were living in the endemic area named Yushan, Jiangxi, including 36 individuals with no fibrotic change in the liver (Grade O) and 156 patients with typical fibrotic change (Grade I through Grade III), diagnosed by ultrasonography (Cairo, 1991). After extensive analysis of HLA-class II region and polymorphic immune response related genes (TNF- $\alpha$ promoter, IL-4R, IL-4 promoter, IL-4, IL-13 promoter, IL-13, region), the HLA-DRB1*1101 and HLADRB5*0101, IL-13 promoter A / A genotypes were revealed to be associated with protection and susceptibility to fibrosis. Moreover, HLA-DRB5*0101 and IL-13P-A / A both of which were susceptible markers to fibrosis were synergisti- 
cally elevated the odd's ratio. This effect was considered to be mediated though IL-13 production up-regulation in the antigen specific CD4+T cells stimulated by HLA-DRB5* 0101.

\title{
A-19) A SURVEY ON ANTIGENEMIA OF WUCHERERIA BANCROFTI AND URINE ANTIBODY TITER IN RURAL COMMUNITIES IN NEPAL
}

\author{
KANJI WATANABE ${ }^{1}$, MAKOTO ITOH ${ }^{2}$, SHINJIRO HAMANO 3 , SHIGERU KOBAYASHI ${ }^{4}$, \\ SASHI SHARMA ${ }^{5}$, GOPAL P, ACHARYA ${ }^{5}$, YOSHIKI AOKI ${ }^{1}$ \\ ${ }^{1}$ Department of Phrasitology, Institute of Tropical Medicine, Nagasaki University, \\ ${ }^{2}$ Department of Phrasitology, Aichi Medical University, \\ ${ }^{3}$ Department of Microbiology and Immunology Faculty of Medical Sciences, Kyushu University, \\ ${ }^{4}$ Department of Human Geography, Graduate School of Letters, Osaka University, Japan \\ ${ }^{5}$ Institute of Medicine, Tribuvan University, Nepal
}

In order to determine the prevalence of the bancroftian filariasis in rural communities in Nepal, serum and urine samples from inhabitants in two rural villages (Judigaun, Kotyang) were examined. Serum and urine samples of 244 inhabitants in Judigaun, which locates $30 \mathrm{~km}$ from Kathmandu, were collected in 2000, 2001. Stored serum and urine samples collected from inhabitants in Kotyang in October 1998 at before survey were also used. Serum samples were examined for $W$. bancrofti antigens by using $\mathrm{Og} 4 \mathrm{C} 3$ assay. Immunoglobulin G4 against filarial antigen in the urine samples were measured by using filarial antigen coated 96-well micro titer plates and peroxidase conjugated second antibodies to human IgG4. Among 238 serum samples and 244 urine samples from Judigaun people, 60 (25.2\%) serum samples and $124(50.8 \%)$ urine samples were positive with regards to $W$. bancrofti antigenemia and filarial IgG4 titer respectively. Among 117 serum samples and 364 urine samples from Kotyang people, 18 (15.4\%) serum samples and $90(24.7 \%)$ urine samples were also positive with antigenemia and IgG4 titer respectively. These results show that rural area are also endemic of $W$. bancrofti and more detailed study will be expected.

\section{A-20) MATHEMATICAL MODEL FOR THE TRANSMISSION OF LYMPHATIC FILARIASIS AND ITS APPLICATIONS}

\author{
HIROYUKI ISHII ${ }^{1}$, HIROFUMI ISHIKAWA ${ }^{2}$, AND YUKIO OHGA ${ }^{1}$ \\ Department of Environmental Synthesis and Analysis, \\ Graduate School of Natural Science and Technology, Okayama University ${ }^{1}$, \\ Department of Environmental and Mathematical Sciences, \\ Faculty of Environmental Science and Technology, Okayama University ${ }^{2}$
}

Our study aims at evaluating the effect of vector control on the prevalence of Iymphatic filariasis caused by Wuchereria bancrofti using computer simulations based on the stochastic transmission model, and especially it is focused on the continuous effect for a post control period.

In Pondicherry, South India, Vector Control Research Centre had carried out the integrated vector control program against filariasis and malaria for five years (1981-1985), and reported a substantial decrease in both vector population and the transmission index for $W$. bancrofti during the period of vector control. We improve the transmission model proposed by A. P. Plaisier et al . (1998) to be fitted for a prevalent situation in Pondicherry on the basis of precontrol epidemiological data there. The population dynamics of mosquito vectors has been simulated by the carrying capacity model of the larval mosquitoes environment.

Our simulations show that in the vector control area the rate of microfilaremia in human population is decreasing slowly while the mean number of L3-larvae carried by mosquito population is decreasing in an early period of a 
control project. For a post control period, they also show that the prevalence revives in a several years and is beyond the initial prevalence level because of a decline of immunity level if an effect of vector control looses thoroughly, but the prevalence stays at low level for a long time if a continuous effect remains at least $10 \%$. We conclude that in a post control period keeping of a little continuous effect contributes to control or elimination of lymphatic filariasis.

\title{
A-21) A TRIAL TO DETECT ANTI-B. PAHANGI IGG4 IN URINE FROM CHILDREN UNDER 5 YEARS OLD IN ORDER TO EVALUATE FILARIASIS CONTROL MEASURES
}

\author{
MAKOTO ITOH ${ }^{1}$, MIRANI V. WEERASOORIYA ${ }^{2}$, NIPUL K. GNAWARDENA ${ }^{3}$, YASUNORI FUJIMAKI ${ }^{3}$, \\ XU-GUANG QIU ${ }^{1}$, EISAKU KIMURA ${ }^{1}$ \\ Department of Parasitology, Aichi Medical University School of Medicine', \\ Filariasis Research Unit, University of Ruhuna, Sri Lanka², \\ Department of Parasitology, Institute of Tropical Medicine, Nagasaki University ${ }^{3}$
}

The global program to eliminate lymphatic filariasis has been launched. For the program, it is essential to find endemic areas and evaluate the effect of control measures. Surveillance of infectious status of young children will be useful for the evaluation, since successful control prevents new infections and children born after the control measures are expected to harbor no filarial parasites.

We developed a sensitive and specific ELISA for bancroftian filariasis using urine samples. In this study, we applied the ELISA method to evaluate filarial infections among young children in a bancroftian filariasis endemic area.

\section{Subjects and Methods}

Urine samples were collected in Matara District, Sri Lanka from 206 children under 5 years old including 38 infants. Samples from their mothers and / or fathers (301 samples) were also collected. Urine collection bags (Atom Pediatric Urine Collector) were used for small children and in- fants. Anti-Brugia pahangi IgG4 antibodies in urine samples were measured by ELISA.

\section{Results and Discussion}

Urine samples from small children could be collected easily and safely. Filaria antigen specific IgG4 antibody were positive in $10.5 \%$ (4/38) of infants ( $\leqq 1$ year old), $7.5 \%(3 / 40)$ of the age group $1-2$ years, $2.3 \%$ (1/43) of the age 2-3 years, $22.5 \%(12 / 47)$ of the age 3-4 years and $26.3 \%(10 / 38)$ of the age $4-5$ years. A remarkable increase in the positive rate was observed at age 3 years old and above, indicating that the filarial infections occur very early in life in this area. The positives in infants have antibodies transferred from their mothers.

These results show that the measurement of filarial antigen specific IgG4 antibodies in urine samples from children is easy and useful for evaluation of the parasite control program.

\section{A-22) RESISTANCE OF BLASTOCYSTIS HOMINIS TO METRONIDAZOLE}

\author{
YOSHIMASA KANEDA ${ }^{1}$, NORIYUKI HORIKI ${ }^{2}$, XUN-JIA CHENG ${ }^{1}$, HIROSHI TACHIBANA ${ }^{1}$ \\ Department of Infectious Diseases, Tokai University School of Medicine'; \\ Division of Internal Medicine, National Mie Chuo Hospital ${ }^{2}$
}

Blastocystis hominis has been found on numerous occasions in the human intestinal tract. Although most cases of $B$. hominis infection are symptom-free, symptomatic infections have been reported, and the pathogenicity of this unicellular organism remains controversial. When a $B$. hominis infection is diagnosed, chemotherapy is usually prescribed. At present, the drug of first choice is metronidazole. We used metronidazole to treat 15 infected individuals whether or not they were symptomatic. Of the 15 infected individuals, 11 proved refractory to treatment even though large doses of metronidazole were administered. Because none of our surveyed individuals were immuno or otherwise 
deficient, any GI symptoms were believed to have been due to the infection with $B$. hominis. It is informative that all symptoms disappeared after treatment. To elucidate the causative factors of the chemotherapeutic failure, we monitored the in vitro effects of metronidazole on $B$. hominis isolates obtained from the refratory individuals both before and after treatment. Metronidazole was effective in inhibiting growth of control isolates obtained from non-treated cases and the reference strain (Nand II), although it took 4 hours to manifest efficacy. In contrast, the refractory $B$. hominis isolates showed a slightly increased resistance in vitro to metronidazole. On the basis of the present results, it seems that treatment failure may have resulted from insufficient exposure to metronidazole and that Blastocystis may acquire a degree of resistance after initial exposure.

\title{
A-23) LONG TERM ERADICATION RATE OF IVERMECTIN THERAPY FOR STRONGYLOIDIASIS ON YORON ISLAND, KAGOSHIMA PREFECTURE
}

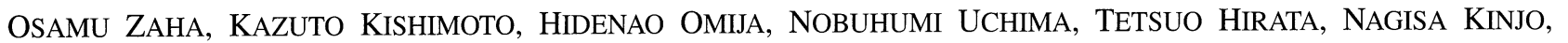 \\ AKIRA HOKAMA, HiROSIHI SAKUgAWA, FUKUnORI KINJO AND ATSUSHI SAITO
}

First Department of Internal Medicine, Faculty of Medicine, University of the Ryukyus

In our present study, we investigated the epidemic of Strongyloides stercoralis on Yoron Island, Kagoshima Prefecture. Furthermore we assessed the long term eradication rate of ivermectin therapy for chronic strongyloidiasis and adverse effects of the drug. Yoron Island is situated in the southernmost area of Kagoshima Prefecture. Of the 611 persons examined by using agar plate culture method, 64 $(10.5 \%)$ were found Strongyloides-positive. By age, the positive rate was highest in $60 \mathrm{~s}(16.0 \%)$, following by $70 \mathrm{~s}$ (13.8\%), 80s (12.5\%), 50s (6.9\%) and 40s (6.5\%), Of those who were found Strongyloides-positive, 32 persons (17 males and 15 females) desired to have treatment. HTLV-1 antibody positive rate was $25.0 \%$ ( $8 / 32)$, of which males were $23.5 \%$ and females $26.7 \%$. To each patient, approximately $100 \mu \mathrm{g} / \mathrm{kg}$ of ivermectin was administered before breakfast. The same treatment was repeated after 2 weeks. During the period of administration of ivermectin, Liver dysfunction was observed in one patient. However, it was of mild with only slight increases in ALT, and no particular treatment was required. As subjective adverse effect, a feeling of vertigo was noted in one patient after administration of 2 courses. In this case, too, no particular treatment was necessary. In the 32 patients who received treatment, the eradication rates in 2 weeks and 4 weeks after first treatment were $100 \%$ (32/32 patients) respectively. In the follow-up investigation conducted one and four year later, 2 cases of recurrence $(30 / 32,26 / 28)$ were found respectively. Both of the 2 patients were HTLV-1 antibody positive.

Ivermectin is being used widely all over the world as a drug for Onchocerca volvulus, and it shows high anthelmintic activity against $S$. stercoralis too. Ivermectin showed excellent anthelmintic effects with mild toxicity. We therefore consider ivermectin is the most useful agent for the treatment of chronic strongyloidiasis at present.

\section{A-24) PREVALENCE OF OXYURIOSIS AND OTHER HELMINTH AT THE SCHOOL OF MOUNTAINEOUS REGION OF NEPAL: INFLUENCE BY TARGET SELECTED AND BLANKET TREATMENT}

\author{
KOSUKE HARUKI ${ }^{1,2}$, TAKASHI FUJINO ${ }^{1}$, MORIYASU TSUJI ${ }^{1}$, JEEVAN BAHADUR SHERCHAND ${ }^{2}$
}

Department of Infectious Diseases, Kyorin University School of Medicine', Infectious and Tropical Disease Research Centre / $\mathrm{Nepal}^{2}$

Helminth is one of major cause of economical loss in developing world. JAITI (Japan Agriculture In-service Training Institute) Basiphant School was established in
1993 at mountainous region located about $80 \mathrm{~km}$ southwest of capital city Kathmandu in Nepal. The school children were treated by mebendazole twice a year since 1993 . We 
have started school health project in 1998. Two hundred forty school children aged six to twenty first were the target. The prevalence of helminth was 60\% at initial time in 1998 and considered that the result was contributed to blanket treatment. We examined the stool and selected positive cases and treated them by albendazole but not any medication to negative cases. One years interval showed high prevalence of helminth over $80 \%$. The result suggested high re-infection rate and necessity of blanket treatment. We have started blanket treatment by albendazole twice a year then after two years later in 2001 the prevalence was decreased to $58 \%$. But the prevalence of Enterobius infection using scotch tape method was $43 \%$ in 1999 and 52\% in 2001. This data indicated several speculation to re-consider the strategy of the project as follows: 1. Target selected treatment is not an adequate method to control helminth infection in the school. 2. Re-infection rate is supposed to be high and even by six months blanket treatment may not be expect to control the prevalence less than 50\%. 3. Health education programme involving families of children has not been performed yet. The infection cycles in each family and community may contribute high re-infection rate at the school. 4. Increased prevalence of Enterobius infection may due to improved technique by children to collect the specimen. 5. Treatment performed twice in a year by albendazole does not decrease the prevalence of Enterobius infection. This may due to high infectivity of Enterobius ova and poor hygienic condition particular clothes and bed linens. 6. Improving hygienic condition by health education may only be able to decrease the prevalence of helminth infection less than $50 \%$ combined with blanket treatment in the school. We are planning to involve families of children then community to health education programme in near future.

\title{
A-25) A SURVEY ON ALLERGY, PARASITIC INFECTION AND NUTRITIOUS STATUS IN SCHOOL CHILDREN IN VIETNAM
}

\author{
YASUNORI FUJIMAKI ${ }^{1}$, DAO TO QUYEN ${ }^{2}$, YUKI SATO ${ }^{3}$, NGUYEN THI DANG ${ }^{4}, \mathrm{HA} \mathrm{HUY} \mathrm{KHOI}^{2}$, \\ DO THI KIM LIEN ${ }^{2}$, YOSHIKI AOKI ${ }^{1}$, SHIGERU YAMAMOTO ${ }^{3}$, FUSAO OTA ${ }^{5}$
}

\author{
${ }^{1}$ Department of Parasitology, Institute of Tropical Medicine, Nagasaki University, \\ ${ }^{2}$ National Institute of Nutrition, Hanoi, Vietnam, \\ ${ }^{3}$ Department of Applied Nutrition, \\ ${ }^{4}$ National Institute of Malariology, Parasitology and Entomology, Hanoi, Vietnam. \\ ${ }^{5}$ Department of Food Microbiology, School of Nutrition, The University of Tokushima,
}

A survey on allergy, parasitic infection and nutritious status in school children in Hanoi, Vietnam was carried out to know relationships among allergy, parasitic infection, and nutritional status. Eighty eight children with an average age of 10.6 years old were examined. For intestinal parasitic infection their feces samples were examined using KatoKatz technique. To survey their allergic diseases or symptoms all the children were done by use of a questionnaire. Daily food intake was assessed by the ' 24 hour recall' method. Their weight and height were measured. Anthropometric indices were analyzed using the standard US National Center for-Health Statistics charts and tables. Body mass index (BMI) was also calculated. Blood samples were collected and analyzed for serum $\operatorname{IgE}$, total protein, albumin and lipid in plasma.

Results: 1) Prevalence of parasitic infection (83.0\%) was very high. Trichuris trichura was a most dominant parasite $(80.7 \%)$. 2) Only 9 children had a history of allergy. Six out of them were infected with parasitic infection and no relationship between the presence of allergy and parasitic infection was observed. 3) The level of total IgE in serum was significantly higher in children with parasite $(474.4 \mathrm{IU} / \mathrm{m} l)$ than that in those without parasite. 4) Nutritional status of chidren examined was poor regardless of parasitic infection. Thirteen and sixteen children were considered to have malnutrition by weight-for-age and heightfor-age analysis respectively. 5) The mean serum level of total protein, total cholesterol, triglyceride etc were all within the normal range. 6) For nutritional intake, the mean energy was $1413.9 \mathrm{Kcal}$, showing about $70 \%$ of recommended dietary allowance in Vietnam. No difference in nutritional intake such as protein, lipid and carbohydrate was observed between the children with and without allergy and parasitic infection.

Conclusions: In Vietnam the prevalence of intestinal parasitic infection was high but the number of children with a history of allergy was few. Nutritional status of children was very poor regardless of parasitic infection. No relation- 
ships between allergy and parasitic infection, and between allergy and nutritional intake were observed.

\title{
A-26) HIV-1 SUBTYPING IN ZAMBIA
}

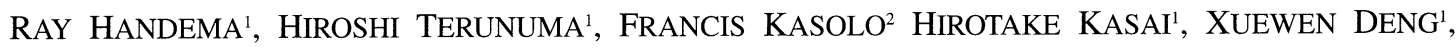 \\ ATSUYA YAMASHITA ${ }^{1}$, NAOKI YAMAMOTO ${ }^{3}$, MITSUO HONDA ${ }^{4}$, MASAHIKO ITO' \\ ${ }^{1}$ Department of Microbiology, Yamanashi Medical University, Yamanashi, \\ ${ }^{2}$ Virology Laboratory, UTH, Lusaka, \\ ${ }^{3}$ Department of Microbiology and Molecular virology, Tokyo Medical and Dental University, Tokyo, \\ ${ }^{4}$ AIDS Research Center, NIID, Tokyo
}

Introduction: Sub-Saharan Africa has the highest HIV prevalence and AIDS burden. The ultimate goal of controlling the HIV-1 pandemic is to develop safe and efficacy vaccines. However, the relatively high level of genetic divergence between the group $\mathrm{M}$ clades has led to the hypothesis that multiple vaccines against HIV-1 may have to be made against the different subtypes of the virus. Sequence information on most of the nine subtypes is currently limited, suggesting that more information will be needed if subtype specific vaccines are to be produced. We are currently carrying out a nation-wide molecular epidemiological study that seeks to access the distribution of HIV-1 subtypes in Zambia. Objective: To document the HIV-1 subtypes circulating in Lusaka, Luapula and Northern provinces in Zambia. Methods: Two hundred and thirty samples collected from antenatal women in seven clinics in Lusaka province were initially screened for HIV using antibody assays. Twenty-five and eight HIV-1 seropositive whole blood samples were collected from provincial headquarters of Northern and Luapula provinces respectively. Molecular epidemiology of HIV-1 subtypes was investigated by direct sequencing of PCR products of gag p17 and env gp120 C2V3-C3 fragments and phylogenetic analysis was done. Results: Sixty-three samples from Lusaka province were HIV-
1 positive. The number of HIV-1 gag p17 and env gp120 sequences obtained per province were 56 for Lusaka, 20 for Northern, and 8 for Luapula. Thus a total of 84 sequences from $92(91 \%)$ HIV-1 positive samples were obtained. HIV1 gag/env subtype C per province were 51 (91\%) for Lusaka, 20 (100\%) for Northern, and, 8 (100\%) for Luapula. One (1.8\%) HIV-1 gag/env subtype A-like, one (1.8\%) HIV-1 gag/env subtype G-like, and one (1.8\%) A/C and one (1\%) D/C recombinants were detected from Lusaka samples. A high conservation of the CTL peptide epitopes was observed among HIV-1 gag and env subtype C-like viruses. conclusions: HIV- 1 subtype $\mathrm{C}$ is predominant in Lusaka, Luapula and Northern provinces. Two new HIV-1 gag/env subtype A-like and subtype G-like have been identified for the first time in Zambia in this study suggesting that more subtypes could be in existence. Two suspected recombinants, $\mathrm{A} / \mathrm{C}$ and $\mathrm{D} / \mathrm{C}$, have also been detected in this study. We are now doing full length genome analysis to determine the nature of recombination of these samples. Some of the more conserved CTL epitopes among different HIV-1 subtypes should be considered in vaccine constructs in order to have cross clade immune responses. There is need for a continued work of HIV subtyping to enhance the efforts being made towards the development of HIV-1 vaccines. 


\title{
A-27) MORECULAR EPIDEMIOLOGY OF HIV IN MYANMAR: EMERGENCE OF NEW FORMS OF HIV-1 INTERSUBTYPE RECOMBINANTS
}

\author{
Y. TAKeBE*1, K. MOTOMURA', S. KUSAGAWA ${ }^{1}$, H. H. LWIN ${ }^{2}$, AND M. ZAW \\ ${ }^{1}$ AIDS Research Center, National Institute of Infectious Diseases, Tokyo, Japan; \\ ${ }^{2}$ AIDS Prevention and Control Programme, Department of Health, Yangon, Myanmar.
}

\begin{abstract}
Background: UNAIDS estimated that 530 thousands people has been infected in Myanmar (as of the end of 1999) since the HIV-1 was introduced in 1989. Highest HIV prevalence is observed among injecting drug users (IDUs) (63\%) and female commercial sex workers (fCSWs) (38\%). In order to study the molecular epidemiology of HIV-1 in Myanmar, we investigated the molecular nature of circulating HIV strains and the interrelationship of the epidemic with those in surrounding countries.
\end{abstract}

Methods: The nucleotide sequences of various segments in HIV-1 genomes were determined and subtyped for 84 specimens from Mandalay, Central Myanmar. The near fulllength sequences of plausible recombinant HIV-1 isolates were determined after PCR-cloning and were subjected to the phylogenetic and recombination breakpoints analyses.

Results: Phylogenetic analyses based on gag (p17) and env (C2/V3) sequences detected 13 subtype C (16\%), in addition to the previously identified subtype B' (Thai-B cluster within subtype B) $(19 / 84,23 \%)$ and CRF01_AE (37/84,
44\%) that are likely to be originated from neighboring Thailand. The majority of subtype $\mathrm{C}$ in Myanmar belongs to the India-China cluster of subtype C. Notably, the remaining 15 specimens (18\%) showed discordance between gag and env subtypes, including 4 gag B'/env $\mathrm{C}$ (B'/C), 3 C/B', C/E and $\mathrm{B}$ '/E, and $2 \mathrm{E} / \mathrm{B}^{\prime}$. These discordant specimens were found most frequently among IDUs $(10 / 34,29 \%)$. The analyses based on near full-length HIV-1 sequences revealed the unique chimeric structures between co-circulating subtypes of B', C and E. in four isolates.

Conclusions: The data suggest that multiple subtypes of B', $\mathrm{C}$ and CRF01_AE are co-circulating in Central Myanmar, leading to the evolution of new forms of HIV-1 intersubtype recombinants. The multiple occurrences of the recombinants with unique genome structures suggested on-going recombination between these three circulating subtypes in Central Myanmar. Our finding would provide information critical for future vaccine strategies aimed at this particular area in Asia.

\section{A-28) TRIALS OF DNA VACCINE TO JAPANESE ENCEPHALITIS VIRUS (JEV): EXPRESSION OF JEV-ENVELOPE PROTEIN IN MAMMALIAN CELLS}

\author{
GUO-He FEnG, Tsutomu TAKegami
}

Division of Tropical Medicine, Medical Research Institute, Kanazawa Medical University

Japanese encephalitis virus (JE) is a serious mosquitoborne viral disease of major public health important in Asia. Recently it has been reported that DNA vaccine is effective to protect the virus infection including JE virus. Expression level of transfected plasmid appears to be related with the efficacy of DNA vaccine. Here we constructed two kinds of expression vectors, pJE and pJME for JE envelope (E) protein and compared the expression level in several mammalian cells. Both expression vectors containing FLAG tag were transfected with liposome (DMRIE-C reagents, GIBCO) into cultured mammalian cell lines, i.e. HepG2 and KN73 derived from human liver, COS-1 and Vero derived from monkey, and BHK cells. To detect expression proteins, Western blot using anti-FLAG or anti-E sera was performed. In the transfected cells, $72 \mathrm{kDa}(\mathrm{prM}+\mathrm{E})$ and 53 $\mathrm{kDa}(\mathrm{E})$ protein were expressed under the control of CMV promoter. The expression of $\mathrm{E}$ protein in the transfection with pJME was usually higher than that of pJE. It is likely that prME protein is cleaved to $\mathrm{E}$ protein in the cells transfected with plasmid. In addition, expression level was dependent on the amounts of DNA transfected, and different among the cell lines. Protein expressions in HepG2, KN73, COS1 were relatively higher than those in Vero and BHK cells. The expression efficacy of $\mathrm{E}$ and other proteins may be influenced by the host factors including peptidase. It is important to check the features of protein expression for the development of an effective DNA vaccine. 


\title{
A-29) EVALUATION OF DENGUE ANTIGEN DETECTION KIT
}

\author{
MAKOTO HARADA ${ }^{1}$, KEN-ICHIRO YAMADA ${ }^{2}$, TOMOHIKO TAKASAKI ${ }^{2}$, ICHIRO KURANE ${ }^{2}$
}

Yokohama Quarantine Station ${ }^{1}$, National Institute of Infectious Diseases ${ }^{2}$

Dengue fever (DF) and dengue hemorrhagic fever (DHF) have been a serious health problem in most of the tropical and subtropical countries in the world. Dengue virus is not endemic in Japan, however, there are imported cases. According to the Japanese new infectious disease control law, which became effective on $1^{\text {st }}$ April 1999, DF/ DHF is one of the infectious diseases to be reported by physicians.

We perform reverse transcriptase polymerase chain reaction (RT-PCR) as one of the laboratory diagnostic methods for virus infection, especially with sera obtained duaring a febrile period. Dengue antigen detection Kit (Globio) has recently been on the market. We examined this test kit for sensitivity and specificity in comparison with RT-PCR.

77 serum specimens were collected from denguesuspected febrile patients and sixty serum specimens (as negative controls) were collected from exanthema subitum patients who had never been to dengue epidemic area. They were tested by RT-PCR, IgM capture-ELISA and Dengue Antigen Detection Kit (Globio).
77 serum specimens collected from febrile patients were divided into three groups by the results of RT-PCR and IgM capture-ELISA. Twenty-two samples in $1^{\text {st }}$ group were RT-PCR (+) and IgM capture-ELISA (-). Twenty-five samples in $2^{\text {nd }}$ group were RT-PCR (-) and IgM captureELISA(+). Thirty samples in $3^{\text {rd }}$ group were RT-PCR (-) and IgM capture-ELISA(-). The results obtained by the antigen detection kit were as follows. (1)Five (23\%) of the 22 samples in first group were determined to be negative. (2)Eight $(32 \%)$ of the 25 samples in second group were determined to be positive. (3) Six (20\%) of the 30 samples in third group were determined to be positive. More over, $5(8 \%)$ of 60 sera from exanthema subitum patients were determined to be positive.

These results demonstrated that this kit has nonspecific reaction and the sensitivity is not as high as RTPCR. However, if high specificity and sensitivity are established by some modification, this technique may be useful for rapid diagnosis, in certain facilities.

\section{A-30) BIOLOGICAL CHARACTERISTICS OF DENGUE 2 VIRUSES ISOLATED FROM PATIENTS WITH DIFFERENT SEVERITIES IN BAN HOM COMMUNE, RURAL AREA OF VIENTIANE, LAO P. D. R.}

\author{
MIKA SAITO, MASAYUKI TADANO AND TOSHIHIKO FUKUNAGA \\ Department of Virology, Faculty of Medicine, University of the Ryukyus
}

Dengue outbreak occurred in a rural commune (Ban Hom, $4 \mathrm{~km}^{2}$ ) Vientiane, Lao PDR in 1994. Five strains of dengue virus type 2 (DEN2) were isolated from patients with different clinical severities in this area within 15 days. In order to identify possible viral factors in the pathogenesis of dengue hemorrhagic fever (DHF) and dengue shock syndrome (DSS), biological characteristics of these 5 strains were compared.

Each strain passaged 3 times in the mosquito cell line C6/ 36 was tested for mouse-neurovirulence, plaque size and virus production in cultured cells, fresh peripheral blood mononuclear cells (PBMC), and dendritic cells. Basic characteristics of the 5 isolates are ; (name: severities, primary or secondary infection, sampling date) 1) UOFP: Fever of unknown origin, primary, June 1, 2) UOFS: Fever of unknown origin, secondary, June 1, 3) DF: dengue fever, secondary, June 15, 4)DHF: DHF grade I, secondary, June 15, 5) DSS: DHF grade III, secondary, June 15. Prototype DEN 2 (New Guinea C strain) was used as a control.

Mouse neurovirulence was determined by intracerebral inoculation in 3-day-old ICR mice with each strain at $10^{4}$ focus forming units (ffu). Death rates at 3 weeks after inoculation of DSS, UOFP were 0\%, DHF 17\%, UOFS 26\%, DF $38 \%$, NGC $100 \%$. Plaque size in C6/36 cells were; UOFP, DHF(7.56-7.95 mm), UOFS, DF, DSS (5.13-5.30 mm). Plaque formation in LLC-MK2 cells was not observed for any of the 5 isolates but for NGC $(1.52 \mathrm{~mm})$. The production of virus particles in culture fluid was determined in $\mathrm{ffu} /$ 
$\mathrm{m} l$ using PAP staining method. $\mathrm{C} 6 / 36$ cells could provide efficient replication of all isolates ranging 3-9x $10^{7} \mathrm{ffu} / \mathrm{m} l$ and $\mathrm{NGC}, 6 \times 10^{8} \mathrm{ffu} / \mathrm{m} l$. LLC-MK2 cell line showed significantly lower production for every isolate $\left(2 \times 10^{3}-3 \times 10^{4}\right.$ $\mathrm{ffu} / \mathrm{m} l$ ) than $\mathrm{C} 6 / 36$. The production of virus particles were not detected in infected culture fluid of PBMC for any of the 5 isolates, while infection of all isolates and NGC in PBMC was confirmed by indirect immunofluorescenece re- action. In immature dendritic cells -like cells generated from PBMC by addin IL-4 and GM-CSF to culture fluid, all 5 isolates could produce virus particles efficiently ranging $1.2-1.8 \times 10^{5} \mathrm{ffu} / \mathrm{m} l$ and have peaks of growth curves at 34 hours after infection.

All biological characteristics studied here did not correlate with the clinical severity of the patient from whom the virus was isolated.

\title{
A-31) COMBINED DETECTION AND GENOTYPING OF CHIKUNGUNYA VIRUS BY A SPECIFIC REVERSE TRANSCRIPTION-POLYMERASE CHAIN REACTION
}

\author{
F. HASEBE ${ }^{1 *}$, M. C. PARQUET ${ }^{1}$, B. D. PANDEY ${ }^{1}$, M. SINNIAH ${ }^{2}$, AND K. MORITA ${ }^{1}$ \\ ${ }^{1}$ Department of Virology, Institute of Tropical Medicine, Nagasaki University \\ ${ }^{2}$ Division of Virology, Institute for Medical Research, Ministry of Health Malaysia
}

\begin{abstract}
A reverse transcription-polymerase chain reaction (RTPCR) was developed for the detection of chikungunya virus (CHIK) infection. Based on the non-structural protein 1 (nsP1) and glycoprotein E1 (E1) genes of CHIK, two primer sets were designed. Total RNA were extracted from the cell culture fluid of Aedes albopictus C6/36 cells inoculated with the S27 prototype virus, isolated in Tanzania in 1953, and the Malaysian strains (MALh0198, MALh0298 and MALh0398), isolated in Malaysia in 1998. For both sets of RNA samples, the expected 354 and 294 base pair (bp) cDNA fragments were effectively amplified from the nsP1 and E1 genes, respectively. The sensitivity of the RTPCR was approximately 5 plaque-forming units (PFU) for the nsP1 primer set and $50 \mathrm{PFU}$ for the $\mathrm{E} 1$ primer set when
\end{abstract}

applied to the S27 strain. RT-PCR products from both S27 and Malaysian strains were sequenced and compared. For the 314 bp-long sequences of the nsP1 gene, the nucleotides were $96.8 \%$ to $97.1 \%$ homologous and the amino acid sequences deduced for the S27 and Malaysian strains were identical. For the $257 \mathrm{bp}$-long sequences of the E1 gene, the S27 prototype and the Malaysian strains showed a $96.5 \%$ and $97.6 \%$ homology for the nucleotide and the amino acid sequences, respectively. Phylogenetic analysis was conducted for the Malaysian strain and other virus strains isolated from different regions in the world endemic for CHIK, using partial E1 gene sequence data. The Malaysian strains isolated during the epidemics of 1998 fell into a cluster along with other members of the Asian genotype.

\section{A-32) A QUESTIONNAIRE SURVEY FOR DENGUE CONTROL IN BLITAR MUNICIPALITY, EAST JAVA PROVINCE, INDONESIA: AN EVALUATION FOR BETTER COMMUNITY EDUCATION APPROACH}

\author{
SISWANTO ${ }^{1,2}$, MASAAKI SHIMADA ${ }^{2}$, RUYONGA JOSEPH ${ }^{2,3}$, TOMOKO KISU ${ }^{2}$, PAIMAN SUPARMANTO \\ Hlth Serv Res Ctr, Natl Inst Hlth Res Dev, MOH, Indonesia ${ }^{1}$, Res Ctr Trop Inf Dis, Inst Trop Med, Nagasaki Univ², \\ District Hlth Serv, Hoima District Local Gov, Uganda ${ }^{3}$
}

The vaccine against Dengue virus infection has not been produced so far. The only method to prevent dengue fever (DF) and dengue hemorrhagic fever (DHF) is the control of vector mosquitoes. In line with these facts, the Ministry of Health of Republic Indonesia has been carrying out an anti-DHF-campaign of mosquito control both via health centers and mass media. In order to assess the effectiveness of the campaign, a questionnaire survey was conducted in a community. The objectives of the study were (i) to explore the knowledge, attitude and practices of the people about DHF control and to identify the relating factors, and (ii) to assess the performance of DHF anti-DHF-campaign. The 
survey was conducted in Blitar municipality, East Java Province, Indonesia. By using multistage random sampling, 198 households from 4 villages (kalurahan) were selected. The head of a household or the other member, such as wives and children, of the household was interviewed by using semi-open questionnaire (guided interview). Analysis was made using SPSS Release 10 (SPSS Inc.). The items in the questionnaire were sex, marital status, position in their family, age, education level, occupation, questions about the source and the mean of dengue information and questions to determine their knowledge, attitude and practice for the control of mosquitoes.

Out of 198 respondents, the heads of the household were 103 consisting of 87 males and 14 females, wives were 74 and children were 21 . The mean age of the respondents was 44.0 with a range of 13-77. Fourteen did not graduate from any school, 83 graduated from elementary school, 41 from junior high school, 54 from high school and 6 graduated from college or university. Twenty four were farmers, 37 were merchants, 22 were civil servants, 22 was working at private company, 33 were unskilled workers and 60 were unclassified.

Although most of the respondents (184/198) were aware of dengue fever (DF) and dengue hemorrhagic fever (DHF), a lot of heterogeneity was observed on their knowledge, attitude and practice. The factors that associate with the heterogeneity will be demonstrated and discussed. 


\title{
B-1) PURIFICATION OF RECOMBINANT TRYPANOSOME ALTERNATIVE OXIDASE
}

\author{
KEISUKE KAWAI ${ }^{1}$, COHICHI NIHEI ${ }^{1}$, YOSHIHISA FUKAI ${ }^{1}$, YOSHISADA YABU ${ }^{2}$, \\ NOBUKO MinAGAWA ${ }^{3}$, KAZUO NAGAI ${ }^{4}$, KIYOSHI KITA \\ ${ }^{1}$ Department of Biochemical chemistry, Graduate School of Medicine, the University of Tokyo, \\ ${ }^{2}$ Department of Medical Zoology, Nagoya City University, Medical School, \\ ${ }^{3}$ Department of Biochemistry, Niigata College of Pharmacy, \\ ${ }^{4}$ Department of Bioengineering, Tokyo Institute of Technology.
}

African trypanosoma is a parasite, which causes African sleeping sickness of human and nagano disease of cattle. Because at present drugs against trypanosomes have strong side effect and are not effective for chronic patients, a new effective drug is awaited now. We found that ascofuranone isolated from Ascochyta visiae inhibits specifically mitochondrial respiration of blood stream form of Trypanosoma brucei brucei at very low concentration. In addition, we found that injection of ascofuranone into infected mice made blood stream form of T.brucei brucei die out.

It is said that the target of ascofuranone is cyanide resistant terminal oxidase located at mitochondrion of blood stream form of T.b.brucei. This enzyme is referred to as TAO (trypanosome alternative oxidase), and functions ubiquinol oxidase unlike cytochrome $c$ oxidase of mitochondrion of mammal. Because mammals don't have TAO that is essential for reoxidation of reducing equivalent generated during glycolysis, TAO is expected as a candidate of target for chemotherapy against trypanosomes. It is also reported that TAO is highly homologous to alternative oxidase of mitochondria of plants, but biochemical analysis has not been carried out due to difficulty of purification. Therefore, we made overexpression of recombinant TAO (rTAO) in E.coli for the purpose of characterization of TAO, and turning ascofuranone to clinical use.

We established the condition on which about 80 percent of membrane fraction from large-scale culture of E.coli was rTAO. And, examination of solubilizing rTAO with various detergents revealed that digitonin is the most suitable detergent to solubilize rTAO. Digitonin-extaracted rTAO was purified by nickel column chromatography and enzyme assay of purified rTAO indicated that ascofuranone inhibited ubiquinol oxidase activity of rTAO competitively with ubiquinol, suggesting that aromatic part of ascofuranone is recognized by ubiquinol binding site.

\section{B-2) DIHYDROOROTATE DEHYDROGENASE CATALYZING SOLUBLE FUMARATE REDUCTASE IN TRYPANOSOMA CRUZI}

\author{
EIZO TAKASHIMA ${ }^{1}$, DANIEL KEN INAOKA ${ }^{1}$, TAKESHI NARA ${ }^{2}$, MASAO ODAKA $^{2}$, TAKASHI AOKI ${ }^{2}$, \\ KOZI INAKA ${ }^{3}$, AND KIYOSHI KITA ${ }^{1}$
}

Department of Biomedical Chemistry, Graduate School of Medicine, University of Tokyo ${ }^{1}$. Department of Parasitology, school of Medicine, Juntendo University ${ }^{2}$.

Maruwa food industry Co.,Ltd.. ${ }^{3}$

Succinate production resulting in reduction of fumarate is one of the essential processes controlling redox homeostasis for many organisms living under anaerobic conditions. However, Trypanosoma cruzi, a parasitic protozoa causing Chargas'disease, excretes a considerable amount of succinate even they uses TCA cycle and aerobic respiratory chain. Thus, it has been believed that unknown metabolic pathways are involved in the succinate production of the parasite. Present study shows the first evidence to characterize soluble fumarate reductase (FRD) of T.cruzi at the molecular level, which has been considered to be a key enzyme to understand the unknown pathways for the succinate production.

We presented here that T.cruzi soluble methylviologen (MV) -FRD consists at least 2 kinds of protein. One of the FRDs is attributable to dihydroorotate dehydrogenase (DHOD), catalyzing oxidation of dihydroorotate (DHO) to form orotate, a 4th enzyme of the pyrimidine de novo biosynthesis pathway. This indicates that not only T.cruzi DHOD functions as a part of the pyrimidine de novo bio- 
synthesis pathway but also the enzyme may play an important role in fumarate/succinate metabolism. Using recombinant T.cruzi DHOD that was expressed in E.coli, it was demonstrated that the DHOD is biochemically belonging to family $1 \mathrm{~A}$ enzymes that is soluble, homodimeric protein containing FMN. T.cruzi has unusual FRDs system in addition of aerobic respiratory chain. Further characterization FRDs of T.cruzi would provide us the complete view of the parasitic metabolism.

\title{
B-3) COMPARATIVE ANALYSIS OF CDNA EXPRESSION PROFILES BETWEEN BLOODSTREAM AND PROCYCLIC FORMS OF TRYPANOSOMA B.BRUCEI USING FLUORESCENT DIFFERENTIAL DISPLY METHOD
}

\author{
OHSHIMA S., SUZUKI T., YABU Y., HATOH M., OHTA N.
}

Dept. Medical Zool., Nagoya City Univ. Med. School

There are 200,000-300,000 Africa narcolepsy patients who are newly infected by Africa Trypanosoma every year. In addition, many domestic animals die from Trypanosoma infection. The Trypanosoma protozoa spread between the mammal host and the tsetse fly vector in its lifecycle. In order to control Trypanosoma protozoa in the future, we analyzed geneexpression profiles between blood stream and procyclic (insect) forms of Trypanosoma brucei brucei using the method of fluorescence differential display.

Briefly, total RNA of long slender, short stumpy and procyclic forms were reverse-transcribed. PCR was performed with combinations of 10-mer arbitrary primer and rhodamine CT16A, G, and C primers. After electrophoresis, differentially expressed cDNA bands were detected with fluorescent image analyzer.

As a result, about 10,000 cDNA (120 primer combinations) were surveyed, and a total of 39 differentially regulated cDNA bands were identified. One markedly differential expressed cDNA, which was upregulated in procyclic form, was selected and sequenced. No high similarity was found for this cDNA fragment, with Genbank database search. Thus, 5'RACE is now under way, for cloning of the full-length cDNA.

\section{B-4) PRELIMINARY ANALYSIS OF GENES EXPRESSED DURING LEISHMANIA PARATITES INFECTION USING CDNA MICROARRAY}

\author{
HIROSHI UEZATO ${ }^{1}$, KIMIKO TAKEI ${ }^{1,2}$, NOOR MOHAMMAD KHASKHELY ${ }^{1}$, MOTOYOSHI MARUNO ${ }^{1}$, \\ SIGEO NONAKA ${ }^{1}$, MASATO UMIKAWA ${ }^{2}$, KEN-ICHI KARIYA ${ }^{2}$, MICHEAL COLlIER ${ }^{3}$, JAMES BRISTOW ${ }^{3}$, \\ EDUARDO A. GOMEZ L ${ }^{4}$, MASATO FURUYA ${ }^{5}$, AND YOSHIHISA HASHIGUCHI ${ }^{6}$
}

\author{
${ }^{1}$ Department of Dermatology and ${ }^{2}$ Department of Biochemistry II, Ryukyu University School of Medicine, \\ ${ }^{3}$ Department of Pediatrics, University of California, San Francisco, USA, \\ ${ }^{4}$ Department Tropical Medicine, University of Guayaquil, Ecuador, \\ ${ }^{5}$ Institute of Laboratory Animal, Kochi Medical School, ${ }^{6}$ Department of Parasitology, Kochi Medical School
}

Purpose; The Leishmania is the causitive agent of leishmaniasis. It multiplies as the extracellular promastigotes and lives and replicates intracellularly in the mammalian macrophages. Macrophages play an important role agansit invasive microorganisms and viruses. It is very interesting why Leishmania parasite inhabits in the phagolysomes. On the other hand, cDNA microarray allows the simultanous parallel expression analysis of many genes. We report analysis data of gene expression during Leishmania parasites infection using cDNA microarray.

Materials and method: Total RNA were extracted from macrophage derived Balb/c mouse (J774-A1) and Leishmania Leishmania major (MHOM/SU/73/5ASKH) infected macrophages for $48 \mathrm{hrs}$ culture. Total RNA derived Leishmania-infected macrophages labeled Cy5 (red) and control RNA labeled Cy3 (green). Two probe are combied, 
then hybridized at $64^{\circ} \mathrm{C}$ to microarray slide. Raw scanning image were processed using microarray image analysis software.

Results and discussion: Comparison between non-infected macrophages and Leishmania-infected macrophages verified the involvement of many genes. About one hundred genes were found to be up-regukated in Leishmaniainfected macrophage. Leishmania afected gene expression of diverse range of cellular pathway and function, including cell adhesion, cytokine, farnesylation, metabolism, RNA handling, signaling, transcripition, transport factor and EST.

\title{
B -5) DEFECT OF LEISHMANIA ANTIGEN-SPECIFIC INTERFERON-G PRODUCTION IN A PATIENT WITH DIFFUSED CUTANEOUS LEISHMANIASIS IN ECUADOR
}

\author{
HAMANO S. ${ }^{1}$, Mimori T. ${ }^{2}$, E. A. Gomez L., M. CAlvopina H. ${ }^{4}$, MARUNO M. ${ }^{5}$, Himeno K. ${ }^{1}$, \\ NONAKA S. ${ }^{5}$, HASHIGUCHI Y. ${ }^{6}$ \\ ${ }^{1}$ Dept. Parasitol., Facul. Med. Sci., Kyushu Univ., ${ }^{2}$ Dept. Tumor Gen. Biol., Kumamoto Univ. Sch. Med., \\ ${ }^{3}$ Dept. Trop. Med., Catholic Univ., ${ }^{4}$ Inst. Immunol., Quito Central Univ., \\ ${ }^{5}$ Dept. Dermatol., Facul. Med., Univ. Ryukyus, ${ }^{6}$ Dept. Parasitol., Kochi Med. Sch.
}

Cutaneous leishmaniasis is clinically divided into classical localized and diffused types. Clinical manifestations of diffused cutaneous leishmaniasis (DCL) are many nodules and papules on the whole body, but no ulcer. Those of localized cutaneous leishmaniasis (LCL) are one or several nodules, papules and ulcers, of which margin elevates like bank. DCL was actually not as rare as it was considered before. Many cases were recognized in the New world, especially in Brazil and Venezuela. DCL Patients shows humoral immunity against leishmania antigens, but not cellular immunity and delayed type hypersensitivity. To clarify leishmanian antigen-specific immune response and pathological characteristic of a patient with diffused cutaneous leishmaniasis.

The study was performed in Ecuador. A DCL patient caused by L. (Leishmania) mexicana, 6 patients with active LCL, 6 patients healed from LCL, 6 healthy doners who have been lived in urban area in Ecuador and were naïve to Leishmania infection were examined for leishmanian antigens-specific immune response. PBMCs prepared from above people were cultured with or without leishmanian antigen, PPD and ConA for 72 hours, and culture supernatants were collected and transferred to Japan. The concentrations of IFN-g and IL-4 in the supernatants were measured by ELISA.

PBMCs prepared from patients with active LCL and those healed from LCL produced enough amount of IFN-g in response to leishmanian antigen, PPD and ConA. Although PBMCs prepared from a patient with DCL also produced enough amount of IFN-g in response to PPD and ConA, but not in response to leishmanian antigen. Six healthy doners who have been lived in urban area in Ecuador also produced enough amount of IFN-g in response to PPD and ConA, but not to leishmanian antigen. IL-4 was not detected in any culture supernatants. Immune system of a DCL patient was shown to be in anergy or deviation to Th 2 against leishmanian antigen. 


\title{
B-6) CLINICAL SURVEY OF CUTANEOUS LEISHMANIASIS IN ECUADOR LAST 10 YEARS (1991 2000)
}

\author{
Motoyoshi MARUnO ${ }^{1}$, ATSUSHI HosoKaWA ${ }^{1}$, HiRoshi UEZATO ${ }^{1}$, SHIGEO NONAKA ${ }^{1}$, \\ GOMEZ E. A. L. ${ }^{2}$ YOSHIHISA HASHIGUCHI ${ }^{3}$. \\ Dept. of Dermatology, University of the Ryukyus ${ }^{1}$, \\ Dept. of Tropical Medicine, University of Catholic Saniago de Guayaquil, Ecuador ${ }^{2}$, \\ Dept. of Parasitology. Kochi medical School ${ }^{3}$.
}

We analyzed clinical and epidemiological data on cutaneous changes of leishmaniasis recorded from 1991 to 2000 in Ecuador. The study areas were included Provinces of Manabi, Los Rios, Bolivas, Pichincha, Azuay, and Esmeraldas located at the Pacific coast and the slope of Andean mountains. A total of 570 cutaneous leishmaniasis patients, 324 males and 246 females, living in Ecuador were examined for this study. Each patient was thoroughly examined clinically and parasitologically. The mean age of the patients was 19.82 years ( \pm 0.89 s.e.) in males, 17.45 years ( \pm 1.00 s.e.) in females and 18.80 years $( \pm 0.67$ s.e. $)$ in total. Patients less than 20 year-old occupied more than half of all the patients examined. The total mean onset of cutaneous lesions was 6.17 months ( \pm 0.41 s.e.); 5.58 months ( \pm 0.39 s.e. $)$ in males, 6.96 months ( \pm 0.56 s.e.) in females. 32 cases $(6.5 \%)$ in total showed the duration period of lesions more than 13 months. The popular types of lesions in- cluded ulcer, nodule, erythematous plaque and papule. The most popular was ulcer formation. The patients with ulcer occupied more than $50 \%$ of the total. More than half of the lesions were located on the face and the extremities. Almost half of the lesions were solitary. The cases with more than ten multiple lesions were seen in a total of 16 patients. Ultrastructural observations showed poor parasitophorous vacuole (PV) formation in the skin specimens in this study. It is needed to examine whethet PV formation should be related to the duration of the diseases. Cutaneous leishmaniasis in Ecuador may differ from the other areas because of the defference of the parasite spesies, various behaviours of the vectors and the different life style of the inhabitants. Therefore, medical doctors assigned to the treatments for cutaneous leishmaniasis in Ecuador have not only medical knowledge but also entomological, ecological, environmental and anthropological knowledge.

\section{B-7) FLAGELLIN FROM BURKHOLDERIA PSEUDOMALLEI STIMULATES PULMONARY EPITHELIAL CELLS TO INDUCE IL-8 PRODUCTION}

\author{
M. SAITO 1, BENJAMAS InTRAOKA 1, K. OIShi 1, A. WADA 2, T. HiRAYAMA 2, T. NAGATAKE 1.
}

Dept of Int Med and Bacteriology, Inst of Trop Med, Nagasaki Univ.

The causative agent of melioidosis, Burkholderia pseudomallei (Bp) is one of the most important causes of mortality of septicemia and acute fulminant pneumonia in Northeastern part of Thailand. Increased plasma levels of IL-8 is associated with a high mortality in cases of septicemia, and is considered to be a better predictor of mortality. In this study, we examined the activity of IL- 8 induction by pulmonary epithelial cell line (A549 cells) in response to the culture supernatant of B.p (CSBP), and determined which components were responsible for IL-8 induction by these cells.

We examined the IL-8 inducing capacity of CSBP of seven clinical isolates, and found potent activities of IL-8 induction in response to CSBP from these strains. A time- and concentration-dependent IL-8 production by A549 cells in response to CSBP (561 strain) was observed. Treatment with proteases and heating of CSBP significantly decreased IL-8 inducing activity. A gel filtration on chromatography of the CSBP on a Superose 12 column demonstrated one separate fractions showing IL- 8 inducing activity. These were estimated to have molecular masses higher than 450 $\mathrm{kDa}$.

Bacterial flagellin has been reported to stimulate NF$\mathrm{kb}$ activation through toll-like receptor 5, which subsequently induces IL-8 production and other cytokines. We, therefore, doveloped an immunoblot assay for condensed filtrate of CSBP (MW cut off $>100 \mathrm{kDa}$ ) employing antiflagellin of B.p antibody. Anti-B.p flagellin recognaized 
the band MW of $43 \mathrm{kDa}$ which corresponding to the known MW of B.p flagellin. These data suggest that one of major IL-8 inducing factors in CSBP strain is flagellin of B.p.
Flagellin of B.p may contribute to dense neutrophil accumulation in the airway of patients with pulmonary mellioidosis.

\title{
B-8) CLINICAL AND MICROBIOLOGICAL CHARACTERISTICS OF RESPIRATORY INFECTIONS AMONG HIV-INFECTED PATIENTS IN NORTHERN THAILAND
}

\author{
NORICHIKA ASOH ${ }^{1}$, HIROSI WATANABE ${ }^{1}$, SINOBU KOBAYASI ${ }^{1}$, KIWAO WATANABE ${ }^{1}$, KAZUNORI OISHI ${ }^{1}$, \\ WEERAYUT KOSITSAKULCHAI ${ }^{2}$, TIPPAYA SANCHAI ${ }^{2}$, KHEMRASSAMEE KUNSUIKMENGRAI ${ }^{2}$, \\ SUMPUM KAHINTAPONG ${ }^{2}$, BANYONG KHANTAWA ${ }^{3}$, PRASIT THARAVICHITKUL ${ }^{3}$, \\ THIRA SIRISANTHANA ${ }^{3}$ AND TSUYOSI NAGATAKE ${ }^{1}$
}

\author{
${ }^{1}$ Dept.of Internal Med., Inst. of Tropical Med., Nagasaki Univ., Japan, \\ ${ }^{2}$ Nakornping Hosp., Thailand, \\ ${ }^{3}$ Dept. of Microbiol., Faculty of Med., Chaing Mai Univ., Thailand
}

Background: Prevalence of HIV infection is increasing in Thailand. However, clinical and microbiological characteristics of respiratory infections among such patients is not clear at present.

Methods: We prospectively analyzed the types and characteristics of respiratory infections in $160 \mathrm{HIV}$-infected patients (161 episodes, 112 males and 48 females, mean age 33.3 years) who were admitted to Nakornping Hospital in northern Thailand.

Result: The mean peripheral blood CD4 lymphocyte count (CD4/CD8) in 105 patients was $60.0 / \mathrm{mm}^{3}(0.1)$. The most common diagnoses included pneumonia in 82 , pneumocystis carinii pneumonia-like interstitial pneumonia in 33, pulmonary mycobacteriosis in 28 , pulmonary nocardiosis in 8 and lung abscess in 8. The most common organisms detectde in the sputum included Haemophilus influenzae (34), Pseudomonas aeruginosa (9), Streptococcus pneumoniae (9), Staphylococcus aureus (8), Penicillium marneffei (7) and Rhodococcus equi (6). Twenty-three cases (14.3\%) had mixed infections. Severe fungal infection caused by Penicillium marneffei in 15, septicemia in 11, lifethreatening meningitis in 4 (cryptococcal in 3 and tuberculous in 1) and were noted, resulting in 20 fatalities (12.4\%). Conclusions: Several types of organisms and respiratory infections exist in HIV-positive patients in northern Thailand. In such cases, early diagnosis and treatment are important for a satisfactory clinical outcome.

\section{B-9) MYCOBATERIAL INFECTION IN THAI CHILDREN INFECTED WITH HUMAN IMMUNODEFICIENCY VIRUS IN THAILAND}

\author{
TERUO KIRIKAE ${ }^{2}$, NARIS WARANAWAT ${ }^{1}$, VIPA TREERATWEERAPHONG ${ }^{1}$, ANURAK MUNSRICHOOM ${ }^{1}$, \\ AKIO NAKAMURA ${ }^{2}$, YASUHITO TOKUMOTO ${ }^{2}$, FUMIKO KIRIAE ${ }^{2}$, NAMIKO MORI ${ }^{2}$, \\ MITSUO HONDA ${ }^{2}$ AND TAWEE CHOTPITAYASUNONDH ${ }^{1}$
}

Queen Sirikit National Institute of Child Health, Bangkok, Thailand ${ }^{1}$,

Department of Infectious Diseases and Tropical Medicine, Research Institute, International Medical Center of Japan, Tokyo, Jpan², Vaccine Research and Development Group, AIDS Research Center, National Institute of Infectious Diseases, Tokyo, Japan ${ }^{3}$

More than ten per cent of chidren, who are born to mothers infected with human immunodeficiency virus-1 (HIV), are still infected with HIV in Thailand. Half of these HIV-infected children contract serious respiratory infections, including tuberculosis (TB) and other common bacterial infections. In the present study, we established a mycobacteriology laboratory in a children hospital in Thailand, and carried out the following TB diagnosis examination for specimens from 105 chilren suspected with tuberculosis infection, including 14 HIV-infected children; acid- 
fast staining, OGAWA eggbased culture, the MIGT culture system (Becton Dickinson) which monitor levels of oxgen by fluorescence, PCR diagnosis (Apmricore, Roch Scientific System) for M.tuberculosis, as well as M.avium and $M$. intracellulare, and a strain-specific DNA-hybridazationbased diagnosis kit, DDH Mycobacteria (Kyokutoh). In 91 HIV-negative children, 7 specimens form 7 children among 81 specimens was positive for M.tuberculosis. No nontuberculous mycobacterium was not detected in these specimens. In $16 \mathrm{HIV}$-infected children, among 16 specimens, 4 specimens from 2 children was positive for M.tuberculosis, 7 specimens from 5 children was positive for nontuberculous mycobacteria, such as M.gordonae, M.Szulgai, M.triviale, M.simia, M.chelonae, M.scrofulaceum and M.intracellulare. Three specimens from 2 patients was positive for both M.tuberculosis and nontuberculous mycobacterium. These results indicates that HIV-infected children were infected with M.tuberculosis as well as nontuberculous mycobacteria.

\title{
B-10) COLLABORATION OF MEDICAL TEAM AND FIELDEPIDEMIOLOGIST DURING THE OUTBREAK OF EBOLA HEMORRHAGIC FEVER IN UGANDA
}

\author{
EMIKO IWASAKI
}

\author{
Sendai Quarantine Station, Ministry of Health, Labor and Welfare
}

On October 16,2000,WHO confirmed that the outbreak of febrile disease in Gulu district of Uganda was caused by Ebola hemorrhagic fever. WHO immediately sent personnel and started necessary measures in collaboration with Ugandan Ministry of Health. At the same time, the WHO requested international support, and the United States, France, Italy and Doctors Without Frontiers dispatched the personnel. Japan provided the financial support in the initial phase. In addition, Japanese government decided to dispatch medical specialists and sent 2 doctors on October 30.

The WHO established teams for the following 5 activities:

1. Field Epidemiology 2. Patient Treatment 3. Diagnostic Laboratory 4. Public Education 5. Management and Support

In this region, the smallest social unit is a nucleus family, and these blood relatives gather and form a colony. The chracteristic of this type of society is that groups of cosely related are scattered in a community. In this society, infectious disease rapidly propagates in the community through family and colony. Therefore, early identification and isola- tion of infected is established became primary activities.

The mobile team identified potential infection from contact early by follow-up of infected, and they were also in charge of education for prophylaxis of the disease and discovering undetected cases through regional patrol.

In the previous outbreaks of Ebola viral hemorrhagic fever, hospital infection and consequent reintroduction to community became a problem. By practicing the barrier nursing technique, the medical team prevent hospital infection.

With the collaboration of the mobile team and the patient treatment team, the outbreak of Ebola viral hemorrhagic fever in Gulu district of Uganda ended in February 2001.

In the outbreak such as Ebola hemorrhagic fever, the social structure affects transmission because of the "infection by contact". Therefore, in controlling these diseases, epidemiological considerations including social structure of community, habit and behavior have to be taken into account, and the collaboration between patient treatment and field epidemiology is essential. 


\title{
B-11) DETOXIFYING EFFECTS OF ACHYRANTHES JAPONICA EXTRACT AGAINST HABU VENOM
}

\author{
KOREBUMI MINAKAMI ${ }^{1}$ AND TYOSEI JITOUZONO²
}

Kagoshima University School of Health Sciences ${ }^{1}$ and Jitouzono Clinic ${ }^{2}$

Achyranthes japonica (Inokozuchi) has been believed as the herb to cure a venomous snake's bite in Kagoshima, Japan. We tried to examine biological effects of Inokozuchi for confirming this ancient tradition.

Leaves from fresh Inokozuchi were cut into pieces and ground into pastes. Pastes were filtered and filtrated liquid was centrifuged at 5,000 rpm for 20 minutes and $5^{\circ} \mathrm{C}$. Supernatant was freeze-dried. Freeze-dried Inokozuchi powder was dissolved in 1/60 M PBS and added Trimeresurus (Habu) venom (Sigma). These were mixtured and left for one hour in a room temperature. Five doses of Habu venom -Inokozuchi mixture were injected to mice and rabbits and calculated anti-lethal (ED50) and anti-hemorrhagic reactions of Inokozuchi extract. Five doses of Habu venomboiled (one minute) Inokozuchi mixture were also injected to rabbits and calculated anti-hemorrhagic reactions of Inokozuchi extract. Tail pinch methtod was used to evaluate an analgesic level in mice administered Habu venom or Habu venom-Inokozuchi mixture.
Survival rates showed that median lethal dose in the mice administered Habu venom was $4.6 \mathrm{mg} / \mathrm{kg}$ of test Habu venom (LD50) and that median lethal dose in the mice administered Habu venom-Inokozuchi mixture was $10.5 \mathrm{mg}$ / $\mathrm{kg}$ of test Habu venom (ED50). The ratio of LD50 to ED50 suggests that Inokozuchi reduced lethal toxicity of Habu venom by half. Fifty micro grams of Inokozuchi decreased hemorrhagic reaction due to Habu venom by $72.3 \%$, although Habu venom-boiled Inokozuchi mixture could not decreased hemorrhagic reaction due to Habu venom. Inokozuchi suppressed tail pinch response due to Habu venom by $60 \%$. Local necrosis could not be suppressed by Inokozuchi.

Therefore, Inokozuchi was proved to be antivenom of Habu venom and that involved effective substances were heat-unstable as a protein. Anti-hemorrhagic reactions of Inokozuchi is presumed to be catabolism of toxic proteins owing to enzymes of Inokozuchi.

\section{B-12) THE USE OF TRAVEL VACCINES BY JAPANESE EXPATRIATES IN DEVELOPING COUNTRIES}

\author{
ATSUO HAMADA, YUKA UJITA AND EIICHI OKUZAWA \\ Japan Overseas Health Administration Center
}

We conducted a survey to clarify the level of use of travel vaccines by Japanese expatriates in developing countries. In 1999, we distributed a questionnaire to Japanese adults (more than 3000) living in Asia (East, South East and South), the Middle East, Africa and Latin America. As a result, 2895 questionnaires were recovered and the data were analyzed.

The analysis showed that 1398 Japanese (48.3\%) were inoculated with some type of travel vaccines before departure. Compared with a similar survey conducted in 1994 and 1998 , the ratio of inoculations $(42.7 \%$ and $45.6 \%$, respectively) was significantly higher $(\mathrm{p}<0.05)$. Japanese in Africa showed the highest percentage $(90.0 \%)$, followed by South Asia (67.1\%), Latin America (48.6\%), South East Asia (43.6\%), the Middle East (37.0\%) and East Asia $(34.5 \%)$. More than $20 \%$ in all areas were inoculated with hepatitis $\mathrm{A}$ and $\mathrm{B}$ vaccines and tetanus toxoid. The ratios were regionally high for rabies vaccine in Africa (44.1\%) and South Asia (39.2\%), yellow fever vaccine in Africa $(84.7 \%)$, and Japanese encephalitis vaccine in South Asia $(26.1 \%)$. In each area, the ratios of meningitis, typhoid fever and cholera vaccines were low. In tropical Africa, the ratios of hepatitis A and B vaccines were around $20 \%$ in 1994, which increased to above $40 \%$ in 1999 . However, the ratio of cholera vaccine decreased from $40.7 \%$ in 1994 to 9.4\% in 1999.

Recently, many Japanese expatriates have begun to use travel vaccines bifore departure. However, more than half still do not use vaccines at all. Therefore, it is vitally important to make Japanese expatriates more aware of the importance and effectiveness of travel vaccines. 


\title{
B - 13) SURVEY ON PATIENTS WITH IMPORTED INFECTIOUS DISEASES ADMITTED TO THE DEPARTMENT OF INFECTIOUS DISEASES
}

\author{
KENJI OHNISHI AND YASUYUKI KATO
}

Department of Infectious Diseases, Tokyo Metropolitan Bokutoh General Hospital

Two hundred ninety two patients were admitted to the Department of Infectious Diseases, Tokyo Metropolitan Bokutoh General Hospital from January 1,2000 to December 31,2000 , and 30 of them were infected with some infectious diseases in foreign countries. Fifteen were Japanese men, 10 were Japanese women, and other 5 patients were foreign people. The presumptive place of contraction was India in 6 patients, Thailand in 4 patients, Philippines in 4 patients, Indonesia in 3 patients, Tanzania in 2 patients, China in 1 patient, Bangladesh in 1 patient, New Caledonia in 1 patient, Australia in 1 patient, Kenya in 1 patient, Nigeria in 1 patient, Uganda in 1 patient, South Africa in 1 patient, Mali or Senegal in 1 patient, Thailand or Nepal or In- dia in 1 patient, and unknown in 1 patient. The number of patients of infectious enteritis was 13 (3 were bacillary dysentery, 2 were Campylobacter enteritis, 2 were enteropathogenic $E$. coli enteritis, 1 was paratyphoid fever, 1 was Aeromonas enterits, and 4 were enteritis due to unknown organism), malaria were 6 (3 were falciparum malaria, 1 was ovale malaria, 1 was falciparum malaria with ovale malaria, and 1 was falciparum malaria with malariae malaria), dengue fever was 3 , AIDS was 3 , pneumonia was 2 , pyeronephritis was 1 , bronchitis was 1 , and entero viral meningitis was 1 . Twenty nine patients became to be well and discharged, but 1 Ugandan man of AIDS was died.

\section{B-14) CURRENT STATUS OF IMPORTED MALARIA IN JAPAN SINCE APRIL, 1999}

\author{
HIROSHI OHTOMO ${ }^{1}$, MIKIO KIMURA ${ }^{2}$, SHIGEYUKI KANO ${ }^{3}$, TSUTOMU TAKEUCHI ${ }^{4}$, \\ MASASHI HAYANO ${ }^{1}$, MASAHIRO KUMAGAI ${ }^{1}$, NAOHIRO WATANABE ${ }^{1}$ \\ Departoment of Tropical Medicine, Jikei University School of Medicine', \\ National Institute of Infectious Diseases ${ }^{2}$, Research Institute, International Medical Center of Japan ${ }^{3}$, \\ Department of Tropical Medicine and Parasitology, Keio University School of Medicene ${ }^{4}$
}

Epidemiologic and therapeutic aspects of imported malaria in Japan have been examined since 1980 by sending questionnaires every year to more than 1,700 major hospitals. The new "Infectious Disease Prevention Law" came into force on April 1,1999. Imported malaria cases from that time till December 31,2000 were analyzed. 227 cases were reported, including 110 vivax malaria cases, 91 falciparum malaria cases, 11 ovale malaria cases, 2 quartan malaria cases, 5 mixed infections cases, and 8 cases due to unknown species. The rate of relapse of vivax malaria is $12.4 \%$ and the rate of recrudescence of falciparum malaria is $2.3 \%$. Two fatal cases with falciparum malaria $(2.3 \%)$ were reported. 179 cases $(78.9 \%)$ were Japanese, and 48 cases were foreigners. 175 cases $(77.1 \%)$ were male, and 52 cases were female. Concerning of possible place of contraction with vivax malaria, 28 cases $(25.5 \%)$ were originated from Indonesia, 17 cases $(15.5 \%)$ from India, 15 cases $(13.6 \%)$ from Papua New Guinea. With falciparum malaria, 14 cases $(15.9 \%)$ were originated from Tanzania or
Kenya, 13 cases $(14.8 \%$ ) from Nigeria, 8 cases $(9.1 \%)$ from Ghana. The purposes of travel for Japanese malaria cases were sightseeing (34.9\%), working for NGOs (12.0\%), working as Japan Oversea Cooperation Volunteers (7.8\%), reporting $(7.8 \%)$, and academic investigations (6.0\%). Concerning the drugs chosen for falciaprum malaria, mefloquine alone occupied $38.6 \%$ and combination therapies occupied $45.5 \%$. Concerning the drugs chosen for erythrocytic stages of Plasmodium vivax, chloroquine alone, quinine alone, Fansidar alone, and combination therapies occupied $67.6 \%, 12.0 \%, 8.3 \%$ and $6.5 \%$, respectively. For prevention of relapse of vivax malaria, primaquine was used in $81.5 \%$ vivax malaria cases. These works were done by the Research Group for Development of Chemothrapeutic Agents against Tropical Parasitic Diseases (supported by the Japanese Ministry of Health and Welfare) and the Research Group for Clinical Evaluation of Orphan Drugs against Imported Tropical and Parasitic Diseases (supported by the Human Science Promotion Foundation). 


\title{
B-15) ANALYSIS OF MALARIA SURVEILLANCE DATA BASED ON INFECTIOUS DISEASE PREVENTION LAW IN JAPAN
}

\author{
KOKI KAKU ${ }^{1}$, HIROSHI TAKAHASHI ${ }^{2}$, TAKAAKI OHYAMA ${ }^{2}$, KEN OSAKA ${ }^{2}$, \\ MIKIO KIMURA ${ }^{2}$, NOBUHIKO OKABE ${ }^{2}$ \\ Field Epidemiology Training Program Japan, National Institute of Infectious Diseases ${ }^{1}$, \\ Infectious Disease Surveillance Center, National Institute of Infectious Diseases ${ }^{2}$
}

\begin{abstract}
Background: Although indigenous malaria was eliminated in Japan in 1962, over 100 imported malaria cases are reported among Japanese travelers to and foreign visitors from endemic areas each year. According to the research of the orphan drugs for tropical diseases, diagnosis and treatment are often delayed, and 110-130 malaria cases were reported each year and a total of 14 deaths were reported from 1990-1999.
\end{abstract}

Methods: To identify the current problems and the public health importance of malaria in Japan and to describe the risk factors for malaria infection and fatal outcome, we analyzed data from the national malaria surveillance system for April 1999 to March 2001. To estimate the number of Japanese travelers and foreign visitors, we reviewed the annual statistical report of legal migrants.

Results: During the study period, 288 malaria cases were reported, 198 in Japanese and 90 in foreigners. Falciparum malaria $(n=116)$ accouted for $60.3 \%$ of the cases from SubSaharan Africa and $24.1 \%$ of the cases from South-East Asia. Six patients (5 Japanese, 1 foreigner) with fatal cases were diagnosed a mean of 11.8 days after onset of symptoms (range, 5-26) and 110 non-fatal cases a mean of 6.7 days (range, 0-90) $(\mathrm{p}=0.32)$. Additional deaths that may have occurred after reporting are not included in the data, because the system does not request such follow-up information.

In 2000,7 million $(39.4 \%)$ out of 17.8 million Japanese travelers went abroad to malaria endemic countries/territories. Among them, 36 malaria cases were reported for Sub-Saharan Africa (174.0 cases/100,000 travelers) and 41 cases $(1.5 / 100,000)$ for South-East Asia (relative risk, 114.5; $\mathrm{p}<0.001)$.

Conclusions/Public Health Impact: Each year, over 100 imported malaria cases are reported among Japanese travelers. Japanese travelers, especially those visiting countries with a high risk for falciparum malaria, need to be educated about malaria prevention and the importance of early treatment. Japanese physicians should ask patients about their travel history and consider malaria in febrile patients returning from malaria endemic countries to avoid delay in diagnosis. The surveillance system should be improved to include the prognosis of cases to enable calculation of the case fatality rate and better assess risk factors for fatal outcomes.

\section{B-16) HOW COULD THE ISTM'S MAILING LIST TRAVELMED BE UTILIZED?}

\author{
MiKIO KIMURA ${ }^{1}$, NOBUHIKO OKABE ${ }^{1}$, YUKA UJITA² AND DAVID O. FREEDMAN ${ }^{3}$ \\ Infectious Disease Surveillance Center, National Institute of Infectious Diseases ${ }^{1}$, \\ Japan Overseas Health Administration Center ${ }^{2}$, \\ Travelers Health Clinic, University of Alabama at Birmingham ${ }^{3}$
}

With the ultimate goal of improving travelers' health, the International Society of Travel Medicine (ISTM) utilizes multiple electronic communication modalities. In order to disseminate and share information, and to improve mutual understandings these means include 1) a web page, 2) mass e-mail distribution through which important alerts and advisories are unilaterally delivered to all 2000 ISTM members, 3) TravelMed, a mailing list on which 450 voluntarily subscribed ISTM members from $>30$ countries are free to propose and interactively discuss travel medicine issues of their own choosing, and 4) GeoSentinel, a surveillance network of 25 sites worldwide reporting on travelrelated illnesses and their geographic origins.

When we analyzed TravelMed postings from May to August 2001, the total number of issues discussed was 106, composed of 81 infectious disease topics and 25 noninfectious diseases topics related to the health of travelers. Among those infectious disease issues about half were on 
vaccination and one fourth on malaria. The number of responses to each issue varied from zero to $\geq 21$, with a peak at 2 responses.

Responses from host-country experts to inquiries about the disease situation in that location or on the availability of a given vaccine or on antimalarial in that country are extremely useful to subscribers. For some discussion topics, contradictory responses are posted. Fortunately in these cases, the respondents often present basic ideas, Personal experiences or the literature from which their opinions are derived. However, more active participation by leading experts in travel medicine should be further encouraged. Overall, TravelMed could be a very useful means of discus- sion and is expected to facilitate improvement of travel medicine practices.

We (M. K. \& Y. U. ) have initiated the provision of Japanese summaries of TravelMed postings. At the moment, these summaries are disseminated on a mailing list operated by the Japan Overseas Health Administration Center in which 140 participants responsible for travelers' health are taking part. By recruiting additional coordinators, the entire contents of TravelMed could be summarized with less burden on each individual. Moreover, we intend to provide these summaries on an independent web page in the near future in order to facilitate the easy availability of the TravelMed archives.

\title{
B-17) CEREBRAL METABOLIC CHANGES IN A PRIMATE MODEL OF SEVERE HUMAN MALARIA AS STUDIED BY POSITRON EMISSION TOMOGRAPHY
}

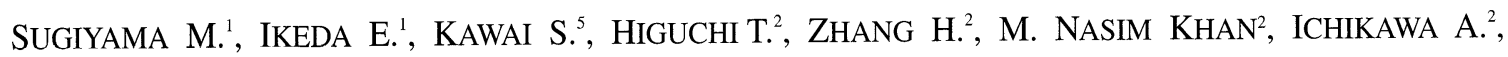 \\ INOUE T. ${ }^{2}$, YAMAGUCHI H. ${ }^{3}$, KATAKURA K. ${ }^{4}$, ENDO K ${ }^{2}$, SUZUKI M. ${ }^{4}$ \\ ${ }^{1}$ Gunma Univ. Sch. Med., ${ }^{2}$ Dept. Nucl. Med., ${ }^{3}$ Dept. Parasitol., ${ }^{4}$ Sch. Health Sci., \\ ${ }^{5}$ Dokkyo. Univ. Sch. Med. Dept. Trop. Med. Parasitol.
}

Plasmodium falciparum infection can cause a severe neurological syndrome termed Cerebral Malaria (CM). CM is seen mainly in children and nonimmune tourists in tropical countries where infection with Plasmodium falciparum is endemic. The neuropathological hallmark of CM had been the sequestration of erythrocytes containing parasites in cerebral capillaries and venules. However, detailed mechanisms of altered consciousness during CM remains controversial. Although there have been several studies on hemodynamic changes in $\mathrm{CM}$, direct measurements on the cerebral metabolic rate of glucose (CMRglc) have not yet been reported at all. In this study, local-CMRglu of Japanese monkeys (Macaca fuscata) infected with Plasmodium coatneyi, a primate model of severe human malaria with cerebral involvement, were studied by using high-resolution positron emission tomography (PET) using 2-[18F] fluoro2-deoxy-D-glucose ([18F] FDG) for the first time. FDG-
PET data for two cases suggest that CMRglc in frontal and temporal cortex was significantly reduced, while those of basal ganglia do not change. CMRglu reduction in cerebral cortex seem to be heterogeneous in severly infected monkey's brain. Reduction of full brain metabolism agree well with the "luxually perfusion" as indicated by previously reported hemodynamic changes in human CM. Neuropathological study of the same monkeys as studies by FDGPET showed that preferential sequestration of parasitized red blood cells appeared in the cerebral microvasculature. However, petechial hemorrhage, focal endothelial cell damage or necrosis were not observed at all in the HE stained brain tissues. This implies that the reduction of CMRglc does not caused by damages in brain parenchyma. We think that the CMRglc reduction in CM may have a protective role to local hypoxia secondary to mechanical blockage of vessels by sequestration. 


\title{
B-18) GLUCOSE METABOLIC CHANGE OF SPLEEN IN MALARIA-INFECTED MACACA FUSCATA: CORRELATION OF FDG-PET RESULTS WITH PATHOLOGICAL FINDINGS
}

\author{
EIJI IKEDA ${ }^{1}$, MUNEHIRO SUGIYAMA ${ }^{1}$, SATORU KAWAI ${ }^{2}$, TETSUYA HigUCHI ${ }^{3}$, HONG ZHANG ${ }^{3}$, \\ M. NASIM KHAN ${ }^{3}$, AKIHIRO ICHIKAWA ${ }^{3}$, TOMIO INOUE ${ }^{3}$, HARUYASU YAMAGUCHI $^{4}$, KEN KATAKURA ${ }^{1}$, \\ KEIGO ENDO $^{3}$ AND MAMORU SUZUKI ${ }^{1}$ \\ Department of Parasitology, Gunma University School of Medicine ${ }^{1}$, \\ Department of Tropical Medicine and parasitology, Dokkyo University School of Medicine², \\ Department of Nuclear Medicine, Gunma University School of Medicine ${ }^{3}$, \\ Gunma University School of Health Science ${ }^{4}$
}

Severe falciparum malaria shows a wide variation in its clinical presentation, such as hypoglycemia, cerebral malaria, renal failure, and pulmonary edema, in addition to the classical features of spikes of fever, hemolytic anemia, and hepatosplenomegaly. These serious clinical symptoms may precipitate various organs into alterations in glucose metabolism. Glucose metabolic changes in severe malaria, however, have not yet been investigated.

In this study, we applied whole body high-resolution positron emission tomography (PET) using 2-[18F] fluoro2-deoxy-D-glucose ([18F] FDG]) in order to detect the effect of malarial infection in glucose metabolism, using Japanese monkey (Macaca fuscata) infected with Plasmodeum coatneyi, aprimate model of severe human malaria. The PET scans were performed for three infected and three uninfected animals. The standard uptake value (SUV), a semiquantitative index of tissue uptake of FDG, was produced for each case. We also examined pathological changes of tissues of various organs.

The SUV of the spleen significantly increased after infection, up to twice to six times as much as that before infection. However, those of the liver, heart, and lung remained unchanged. Pathological examinations of the splenic tissues revealed marked expansion of white pulps, strong expression of MHC class II molecules on B cells and dendritic cells in lymphoid follicles, and enlargement of macrophages which had phagocytosed malarial pigments. These pathological findings suggest the activation of the inflammatory cells in the spleen. The activation of these cells probably caused the significant rise in splenic glucose metabolism.

\section{B-19) CEREBRAL RING HEMORRHAGES IN SQUIRREL MONKEYS INFECTED WITH PLASMODIUM FALCIPARUM}

\author{
YUKO KATAKAI ${ }^{1}$, BASUKI SUKMAWATI ${ }^{1}$, SYOSAKU HATTORI ${ }^{2}$, \\ TAKASHI ONODERA ${ }^{1}$, YOSHITSUGU MATSUMOTO ${ }^{1}$
}

\author{
Department of Molecular Immunology, University of Tokyo ${ }^{1}$, \\ Amami Laboratory of Injurious Animals, Institute of Medical Science, University of Tokyo ${ }^{2}$
}

The severity of neurological symptoms in malaria patients might be correlated with cerebral pathologic features in the brain. Ring hemorrhages are frequently found in the brains of patients with falciparum malaria. We report here the squirrel monkeys infected with plasmodium falciparum Indochina-I/CDC revealed cerebral ring hemorrhages similar to that observed in human malaria cases.

Bolivian squirrel monkeys (Saimiri sciureus boliviensis) were used in this study. A splenectomised monkey was inoculated intravenously with cryopreserved parasitized red blood cells (PRBC) infected with P. falciparum Indochina-I
/CDC as a donor of fresh PRBC. On day 16, the blood was collected and followed by removing plasma, white blood cells and PRBC containing mature stage parasites. The fresh erythrocytes include with $10^{9} \mathrm{PRBC}$ were inoculated to spleen-intact monkeys. Peripheral blood was collected and the parasite counts on Giemsa stained thin blood films were monitored every day. Clinical signs were also observed daily. Neurological signs were assessed in accordance with "Blantyre coma scale" presented by world health organization. Between 7 and 11 days after inoculation, autopsy or necropsy was done. Histopathological ex- 
amination was performed on their cerebrum and cerebellum PRBC were found on day 1 followed by abrupt development of parasite counts. Clinical signs included anorexia, inactivity, convulsions and lethargy occurred about 1 week after the inoculation. In several monkeys, coma scale reached at $<3$ as the state of unrousable coma. In gross findings, petechiaes were seen on the cut surface of white matter in the cerebrum and the cerebellum. In microscopic findings, ball, ellipse or ring shaped hemorrhages were seen in the cerebral and cerebellal parenchyma. These hemorrhages were usually situated around the occluded vessels in the white matter of the cerebral tissue just below the cortex. In the cerebellum, hemorrhages were generally adjacent to the granular layer within the white matter. They were 200 $\sim 500 \mu \mathrm{m}$ size in the major axis. In ring hemorrhages, a perivascular necrotic zone separated the exravasated erythrocytes from blood vessels.

In summarry, bolivian squirrel monkeys inoculated with $P$. falciparum Indochina-I/CDC infected fresh erythrocytes caused cerebral disorder and hemorrhagic lesions which is typical of human cerebral malaria. Due to difficulty of obtaining fresh tissues from patients, mechanism for the occurrence and participation in the neurological symptoms remain obscure. Understanding of the mechanisms would greatly benefit from the existence of a model for cerebral malaria in an experimental host closely related to man. Bolivian squirrel monkey might be a good model for studying ring hemorrhages associated with human falciparum malaria.

\title{
B-20) IDENTIFICATION OF MALARIAI ANTIGEN-MIMICKING PEPTIDES
}

\author{
DAI ISHIKAWA ${ }^{1}$, EIJI NAGAYASU ${ }^{2}$, YAMAJI NAKANO ${ }^{2}$, MAYUMI AKAKI ${ }^{2}$, SORNCHAI LOOAREESUWAN ${ }^{3}$, \\ MASAMICHI AIKAWA ${ }^{2}$, AND TAKAO TAKI ${ }^{1}$ \\ ${ }^{1}$ Molecular Medical Science Institute, Otsuka Pharmaceutical Co. Ltd., \\ ${ }^{2}$ Total Science Technology Institute, Tokai University, \\ ${ }^{3}$ Faculty of Tropical Medicine, Mahidol University
}

Malaria antigen-mimicking peptides were selected by biopanning using a pentadecamer random peptide displayed phage library and anti-malarial anti-sera from 5 plasmodium falciparum-infected patients. Seventy-five positive phage clones were selected by ELISA assay after 3rd round biopanning. From the sequence analysis, 8 positive phage clones were classified as patient IgG-binding peptides and 34 clones were classified as IgM-binding peptides. There were several consensus alignments in IgG-and IgM-binding peptides. Each consensus alignment-bearing phage clone showed the same or similar reactivity pattern in their classes when binding affinity of the 42 individual phage clone to 20 patient sera and 10 control sera were examined by ELISA, suggesting the consensus alignments are critical for binding to the antibodies. When mixed 4 represent peptides were used for ELISA, the mixed peptides reacted with $40 \%$ and $10 \%$ of the patient sera from the uncomplicated malaria and those from sever and complicated malaria, respectively. Whether the relationships between symptoms and the reactivity are presence or whether the antibodies against these peptides inhibit the malarial infection are under studying. 


\title{
B-21) CONSTRUCTION OF ANTI-P. FALCIPARUM/ANTI-CD3 BISPECIFIC scFv WITH ANTIPARASITICIDAL FUNCTION
}

\author{
YoShidA S., KobaYASHi T., ARAI R., Matsuoka H., ISHII A.
}

Dept. Med. Parasitol., Jichi Med. Sch.

A novel bispecific single-chain antibody fragmernt (biscFv) has been constructed to address the possibility of a new malaria therapeutic drug development. The biscFv consists of two different single-chain antibody fragments linked by a flexible peptide linker $\left(\mathrm{Gly}_{4}-\mathrm{Ser}\right)_{3}$. One specificity of the two Fv fragments is directed against MSP-1 molecule on the surface of Plasmosium falciparum merozoites and the other is directed against the CD3 antigen of human T cells; the former reacts with any strains of $P$. falciparum but doesn't have the growth inhibition activity. The construct was expressed in insect cells using recombinant baculovirus system. The antigen-binding properties of the biscFv are indistinguishable from those of the correspond- ing univalent single-chain antibody fragments. In the presence of human peripheral blood mononuclear cells (PBMC), the biscFv specifically induced IFN- $\gamma$ and TNF- $\alpha$ in $P$. falciparum in vitro culture. These data suggest that the bridge formation between malaria parasites and $\mathrm{T}$ cells induces cytokine production at high level near the parasites, presumably resulting in activating NK cells and macrophages and then killing the parasites in vivo. Thus, the biscFv possesses highly selective malaria targeting properties and activates $\mathrm{T}$ cells simultaneously. Cell-mediated immune response induced by the biscFv could be great advantage for the passive immunotherapy against malaria infection.

\section{B-22) PLASMODIUM VIVAX TRANSMISSION-BLOCKING VACCINE: EFFICACY STUDY ON HUMAN ISOLATES}

\author{
TAKAFUMI TSUBOI ${ }^{1}$, JETSUMON SATTABONGKOT ${ }^{2}$, HAJIME HISAEDA ${ }^{3}$, \\ MAYUMI TACHIBANA ${ }^{1}$, MOTOMI TORII ${ }^{1}$
}

\author{
Department of Molecular Parasitology, Ehime University School of Medicine, Japan ${ }^{1}$, \\ Department of Entomology, Armed Forces Research Institute of Medical Sciences, Thailand ${ }^{2}$, \\ Department of Parasitology and Immunology, University of Tokusima, School of Medicine, Japan ${ }^{3}$
}

Antibodies against Plasmodium vivax ookinete surface proteins expressed in yeast (yPvs25 and yPvs28) were produced in mice. Theses sera elicit potent transmissionblocking activity to $P$. vivax Sall strain. To test the efficacy of this vaccine candidate in the natural parasite populations, antisera against yeast expressed recombinant proteins, yPvs 25 and yPvs 28 , were produced in mice and rabbits. The efficacies of the antisera were tested with human isolates at malaria clinics in northwestern Thailand. Blood was collected from patients who came to the clinics and whose blood smears was positive for P. vivax. Antibodies from either mice or rabbits were diluted with normal human serum and added to patients' red blood cells. After mixing the infected blood was fed to Anopheles dirus using membranefeeding method. Mouse serum immunized with PfMSP1- 19expressed in yeast or pre-immunized rabbit serum was used as control for mosquito feeding. Mosquito infection was observed on day 7 post blood feeding. Ten to twenty mosquitoes were dissected for midguts and examined for oocyst development. Number of oocyst was recorded and compared among different treatments. For most human isolates, sera from mice immunized using alum as adjuvant showed complete inhibition of oocyst development. Sera from rabbits immunized with yPvs 25 or yPvs $28+$ alum was less inhibitory than the mouse sera. Sera from rabbits immunized with yPvs 25 or yPvs 28 + Freund's adjuvant was more inhibitory, but still less than the mouse sera. The inhibitory activity correlated with the antibody titer measured by ELISA on recombinant protein. 


\title{
B-23) AN ATTEMPT TO IDENTIFY GENES CONTROLLING SUSCEPTIBILITY TO MOUSE SEVERE MALARIA
}

\author{
EIJI NAGAYASU ${ }^{1}$, MAYUMI AKAKI ${ }^{1}$, YAMAJI NAKANO ${ }^{1}$, SATOSHI MAKINO², GEN TAMIYA², \\ KOICHI NAGAKURA ${ }^{3}$, MASAMICHI AIKAWA ${ }^{1}$ \\ Researcn Institute of Science and Technology, Tokai University ${ }^{1}$, \\ Division of Molecular Life Science, Tokai University School of Medicine ${ }^{2}$, \\ Division of Infectious Diseases, Tokai University School of Medicine ${ }^{3}$
}

Plasmodium berghei ANKA ( $\mathrm{PbA})$ infection in the $\mathrm{C}$ 57BL/6 (B6) strain of mice leads to the development of experimental severe malaria (ESM) and kills almost all of the animals 6-12 days after infection. In contrast, the DBA/2 (D2) strain of mice shows strong resistance to ECM, a majority of animals survive from ECM and dies 20 to 30 days after infection by other malaria-related complications, such as severe anemia and hyperparasitemia. So far, little is known about the genetic basis that accounts for the different susceptibility to ECM. In order to localize such genes on the mouse linkage map, we carried out a genome wide screening using an $F_{2}$ intercross population of susceptible (B6) and resistant (D2) strains.

Experimental infections were achieved by intraperito- neal inoculation of $1 \times 10^{5}$ parasitized red blood cells. $F_{2}$ animals were phenotyped either as ESM susceptible or as ESM resistant based on survival until day 14 after infection.

Prior to the infection, genomic DNA were prepared from mice. A total of 93 informative microsatellite loci along all autosomes and X-chromosome were genotyped. Marker-Trait associations on each marker were assessed by chi-square tests.

We identified a genetic region on mid-chromosome 18 that showed statistically significant linkage to ESM susceptibility. We will continue to make effort to identify a true ESM susceptibility gene on this region by both positional and functional approach.

\section{B-24) BIOCHEMICAL ANALYSIS OF COMPLEXII FROM PLASMODIUM FALCIPARUM MITOCHONDRIA}

\author{
MI-ICHI FUMIKA ${ }^{1}$, TAKASHIMA EIZO ${ }^{1}$, TAKEO SATORU ${ }^{1}$, KOBAYASHI TAMAKI ${ }^{1}$, \\ TAKAMIYA SHINZABURO ${ }^{2}$, KITA KIYOSHI ${ }^{1}$
}

${ }^{1}$ Grad. Sch. Med., Univ. Tokyo, ${ }^{2}$ Dept. Parasitol., Juntendo Univ.

Since the energy metabolism of Plasmodium falciparum is quite different from that of mammalian host, the enzymes of energy transducing pathway of the parasite are promising targets of anti-malaria drugs. Energy requirement during the erythrocyte stage is provide by metabolizing glucose by anaerobic gycolysis. A functional TCA cycle is absent and ATP synthase has not been characterized in this stage mitochondria because $\alpha$-ketoglutarate dehydrogenase doesn't function.

However, recent studies have shown the presence of functional respiratory chain in Plasmodium mitochondria, and the new anti-malarial drug, atovaquone, has been shown to inhibit the electron transfer of the $b c_{1}$ complex (complex III) and to collapse the mitochondrial membrane potential. The presence of an NADH-ubiquinone oxidoreductase (complex I) has been suggested by ability of NADH -linked substrates, such as glutamate, to stimulate ADP phosphorylation in trophozoites treated with digitonin. Evidently, mitochondrial electron transport system is essential for the survival of plasmodium in the host, although ATP is supplied mainly by glycolysis.

Complex II is one of the respiratory components and is the oxidization-reduction enzyme, which catalyzes conversion of succinate and fumarate. Complex II plays a key role in the energy metabolism of parasites such as Ascaris suum. The mitochondrial respiratory chain of $A$. suum changes dramatically during the life cycle. Complex II from the mitochondria of adult $A$. suum exhibits high quinol-fumarate reductase (QFR) activity and plays a key role in anaerobic metabolism as a terminal oxidase in the NADH-fumarate oxidoreductase system. In contrast, complex II from freeliving third stage 1arvae (L3) shows much lower FRD activity, and functions as a succinate dehydrogenase (SDH) during aerobic respiration. If it considers that malaria parasite 
growths under low oxygen, also in P. falciparum, it is likely that complex II functions as QFR and plays an important role in an energy metabolism system. Saraveratum et al . have purified complex II of $P$. falciparum, and we have cloned the genes of enzyme for the catalytic subunits, $S D H A$ for flavoprotein $(\mathrm{Fp})$ and $S D H B$ for the iron-sulfur protein (Ip).

In the present study, using $\mathrm{N}_{2}$ cavitation, we established a protocol to prepare the active mitochondria from plasmodium falciparum. This mitochondrial fraction showed SDH and SQR (Succinate-ubiquinone oxidoreductase) activity of complex II. The specific activity of SDH and SQR $(5.64 \mathrm{nmol} / \mathrm{min} / \mathrm{mg}$ and $4.74 \mathrm{nmol} / \mathrm{min} / \mathrm{mg}$, respectively, at $25^{\circ} \mathrm{C}$ ) was higher than that of the homogenate from the saponin-treated $P$. falciparum (approx. $1 \mathrm{nmol} /$ $\mathrm{min} / \mathrm{mg}$, at $37^{\circ} \mathrm{C}$ ) reported by Suraveratum et al .. The malarial enzyme activity was inhibited by competitive inhibitor malonate, but a known inhibitor of mammalian mitochondrial SDH, 2-thenoyltrifluoroacetone (1mM), had no inhibitory effect on the malarial SDH activity. The chalcone showing antimalarial activity against the in vitro growth of $P$. falciparum had no inhibitory effect on the malarial SDH activity, although rat mitochondria was inhibited by Licochalcone A which inhibits the activity of fumarate reductase (FRD) of Leishmania major promastigote. These results suggest property of malarial complex II is different from that of the host mammalian enzyme. Thus. It could be an excellent target for antiprotozoal drugs.

\title{
B-25) MOLECULAR CHARACTERIZATION OF A1-CYS PEROXIREDOXIN FROM THE HUMAN MALARIA PARASITE PLASMODIUM FALCIPARUM
}

\author{
SHIN-ICHIRO KAWAZU ${ }^{1}$, KANAKO KOMAKI ${ }^{1}$, SATORU KAWAI ${ }^{2}$, NOZOMU IKENOUE ${ }^{3}$, \\ HIROYUKI ISHIKAWA ${ }^{1}$ AND SHIGEYUKI KANO ${ }^{1}$ \\ Research Institute, International Medical Center of Japan ${ }^{1}$, \\ Department of Tropical Medicine and Parasitology, Dokkyo University School of Medicine², \\ Gunma University School of Health Sciences ${ }^{3}$
}

The human malaria parasite Plasmodium falciparum is exposed to reactive oxygen species that are generated from its endogenous metabolism (e. g. haemoglobin digestion) and during external attack by the host immune system. In addition, several anti-malarial drugs (e. g. chloroquine and artemisinin) can burden the parasite with substantial oxidative stress as a part of their anti-malarial effects. Peroxiredoxins are recently described family of antioxidants that are ubiquitous in living cells for metabolizing hydrogen peroxide and hydroxy 1 radicals. We report here the molecular cloning and characterization of a 1-Cys peroxiredoxin from $P$. falciparum. Approximately 250 bp of the 5' region of peroxiredoxin cDNA was obtained from the $P$. falciparum expressed sequence tags (ESTs). The missing 3' region of the cDNA was amplified from the trophozoite mRNA by rapid amplification of cDNA ends (RACE) technique. The full-length cDNA of the parasite's peroxiredoxin (PfPrx-2) encoded a 220 amino acid polypeptide with a predicted molecular mass of $25.2 \mathrm{kDa}$. The presence of the PVCT consensus sequence flanking the conserved Cys47 confirmed that the PfPrx-2 was the 1-Cysperoxiredoxin. This is the first report of 1-Cys peroxiredoxin in protozoan parasites. The antioxidant activity of eliminating hydrogen peroxide by the recombinant PfPrx-2 protein was demonstrated using the ferrithiocyanate system. An elevated expression of the PfPrx-2 protein seen in cytoplasm of the trophozoites, the stage with active metabolism, suggests an association of the peroxiredoxin with the parasite's intracellular redox control. 


\title{
B-26) EFFECT OF MINOCYCLINE IN COMBINATION WITH ANTIMALARIA DRUG ON THE ELIMINATION OF PLASMODIUM BERGHEI AND CHLOROQUINE RESISTANT-P. CHABAUDI PARASITES IN MICE
}

\author{
KIYOMI HANDO ${ }^{1.2}$, QUING HUA LIN ${ }^{1}$, KEN KATAKURA ${ }^{1}$ AND MAMORU SUZUKI ${ }^{1}$ \\ Department of Parasitology, Gunma University School of Medicine ${ }^{1}$, \\ Department of environmental health and laboratory sciences, Gunma University Graduate School of Health Sciences ${ }^{2}$
}

The emergence and spread of drug resistant plasmodium falciparum is a major problem for chemotherapy of malaria. Development of potent anitimalarial is important, but it is also necessary to investigate the possible use of antimicrobial agents with wide spectrum effect, which have already been accepted for clinical use in patients with various infectious diseases. A group of tetracyclines has been used for the treatment of drug-resistant falciparum malaria. Tetracylines were usually combined with qunine since these antibiotics require a longer time for an appearance of the inhibitory effect than other antimalarial drugs.

We previously reported that minocycoline (MC) showed more strong inhibitory activity against in vitro growth of drug-resistant $P$. falciparum parasites than conventional tetracycline and doxycycline. In the present study, we examined whether MC is useful for treatment of murine malaria when it is combined with artemether (AM) or chloroquien (CQ). Random bred ICR mice were intraperitoneally inoculated with $1 \times 10^{5}$ erythrocytes infected with $P$. berghei NK65 strain and the parasitemia was followed.
Mice treated with MC alone at a does of up to $50 \mathrm{mg} / \mathrm{kg}$ for 7 days or AM alone at a dose of up to $2.5 \mathrm{mg} / \mathrm{kg}$ for 4 days were all dead. However, when mice were treated with $\mathrm{MC}$ $(50 \mathrm{mg} / \mathrm{kg})$ for 7 days in combination with AM $(2.5 \mathrm{mg} / \mathrm{kg})$ for 4 days, all mice were cured. In the next experiment, mice were intraperitoneally inoculated with $1 \times 10^{6}$ erythrocytes infected with $P$. chabaudi 3CQR strain, with showed CQ-resistant phenotype. Mice received CQ at a dose of 5 $\mathrm{mg} / \mathrm{kg}$ for 4 days exhibited a similar level of parasitemia compared with that observed in untreated control mice, although an appearance of parasitemia was delayed in the treated mice. However, when mice were treated with CQ $(5 \mathrm{mg} / \mathrm{kg})$ for 4 days in combination with $\mathrm{MC}(50 \mathrm{mg} / \mathrm{kg})$ for 7 day, parasites in the peripheral blood was completely eliminated. These findings suggest that minocycline should be further studied in clinical cases as an excellent candidate for chemotherapy of chloroquine-resistant malaria in combination combined with other antimalarials such as artemether and even with chloroquine.

\section{B-27) ANTI-MALARIAL EFFECTS OF DIPYRIDAMOLE in vitro and in vivo}

\author{
YAMAJI NAKANO ${ }^{1}$, EIJI NAGAYASU ${ }^{1}$, MAYUMI AKAKI ${ }^{1}$, SHIN-ICHIRO KAWAZU ${ }^{2}$, \\ SHIGEYUKI $\mathrm{KANO}^{2}$, MASAYOSHI ITOH $^{3}$, MASAMICHI AKIKAWA ${ }^{1}$
}

\begin{abstract}
Research Institute of Science and Technology, Tokai Univ ${ }^{1}$, Research Institute, International Medical Center of Japan ${ }^{2}$, The Foundation of Research Institute for Production Development ${ }^{3}$
\end{abstract}

We examined anti-malarial effects of dipyridamole (DIP), a coronary vasodilator, in vitro and in vivo. Plasmodium falciparum Indochina 1 (IC-1), a chloroquine (CQ)sensitive strain, and K-1, a multi-drug-resistant strain were grown in the presence of DIP or CQ. At $72 \mathrm{hr}$ culture time, DIP reduced $50 \%$ of parasitemias in IC- 1 and $\mathrm{K}-1$ cultures at concentrations of about 50 and $70 \mu \mathrm{M}$, respectively. In both cultures of IC-1 and K-1, CQ reduced the parasitemias in the presence of 10 or $50 \mu \mathrm{M}$ DIP more effectively than in the absence of DIP. Parasitemias in IC- 1 and K-1 cultures incubated with $500 \mu \mathrm{M}$ DIP treated red blood cells (RBCs) were lower than those in cultures with DIP-non treated $\mathrm{RBCs}$, suggesting that parasitemias decreased as the result of DIP binding to the RBC membrane. We examined effects of DIP on survival rates of C57BL/6N mice infected with Plasmodium berghei ANKA. Among ten infected mice, eight mice died at 10th day after infection, whereas two mice died among the infected mice administrated with DIP (1 $\mathrm{mg} /$ day/mouse) for three days via the tail vein. These results suggested that DIP had anti-malarial effects both in vitro and in vivo. 


\title{
B-28) DEVELOPMENT OF NEW ANTIMALARIAL DRUG-IN VITRO AND IN VIVO ANTIMALARIAL ACTIVITY OF ENDOPEROXIDES
}

\author{
KANAKO ONO ${ }^{1}$, NAOKI OGURA ${ }^{1}$, HYE-SOOK KIM ${ }^{1}$, KHURSHIDA BEGUM ${ }^{1}$, YOHEI OKUDA ${ }^{1}$, \\ KEN-ICHI SUZUKI ${ }^{1}$, KOHEI YOSHITANI ${ }^{1}$, YOSHIAKI HAMADA ${ }^{2}$, YUJI NONAMI ${ }^{2}$, TAKAHIRO TOKUYASU ${ }^{2}$, \\ ARAKI MASUYAMA ${ }^{2}$, MASATOMO NOJIMA² AND YUSUKE WATAYA ${ }^{1}$
}

Faculty of Pharmaceutical Sciences, Okayama University ${ }^{1}$, Faculty of Engineerings, Osaka University ${ }^{2}$

\begin{abstract}
A number of medicines such as chloroquine and quinine are available for treatment of malaria, but the rapid developments of drug resistance are serious problems. Medicinal agents based on novel mechanisms of action are, therefore, required to overcome emergence of resistance and to control an ever-increasing number of epidemics caused by the malaria parasite.

We have confirmed the potential of $1,2,4,5$ tetraoxacycloalkanes as a new class of simple peroxide antimalarial drugs. In the preliminary study, some 1, 2, 4, 5teraoxacycloalkanes have been found to be available for chloroquine-sensitive and -resistant $P$. falciparum in vitro. Especially, 1, 2, 6, 7-tetraoxaspiro [7.11] nonadecane (N89) has a potent antimalarial activity for $P$. falciparum that the $\mathrm{IC}_{50}$ value for FCR-3 strain is $2.5 \times 10^{-8} \mathrm{M}$, that for $\mathrm{K} 1$ strain is $2.6 \times 10^{-8} \mathrm{M}$ and the selective toxicity $(>300)$ is also remarkable. In addition, we investigated the in vivo antimalarial activity of N-89 by 4-day suppressive test. The $\mathrm{ED}_{50}$ value of N-89 has shown $12 \mathrm{mg} / \mathrm{kg} /$ day (ip), which was required to cause $50 \%$ suppression of $P$. berghei in mice. In the experiments, the dose of $50 \mathrm{mg} / \mathrm{kg} /$ day of five of $\mathrm{N}-89$ treated mice were all cured, in which malaria parasites were not observed in circulating blood streams after 60 days.
\end{abstract}

Furthermore, no side effects such as diarrhea, body weight loss and mortality were observed during treatment with $1,600 \mathrm{mg} / \mathrm{kg}$ of $\mathrm{N}-89$ (ip). As a control, mice treated with artemisinin $(50 \mathrm{mg} / \mathrm{kg} / \mathrm{day}$, ip) were not cured and mice died due to $P$. berghei infection.

We evaluated the effect of oral treatments of N-89 (160 $\mathrm{mg} / \mathrm{kg}$ ) for three consecutive days beginning on the day of $1 \%$ parasitemia. Parasitemia declined have been found after 24 hours of drug administration, all mice were cured with no parasite reincrease or toxicity. Conversely, on similar treatment with artemisinin, malaria parasites were still observed in their blood streams, parasitemia become increased again. Our studies indicate that N-89 has a strong and continuous antimalarial activity.

To determine the mechanism of action, morphological changes of malaria parasites during the treatment of $\mathrm{N}-89$ against $P$. falciparum were studied. After treatment with 100 times the $\mathrm{EC}_{50}$ value of $\mathrm{N}-89$, we have observed a condensation of parasite nuclei, shrinked cytosol, inhibition of early and middle trophozoite parasite and little hemozoin formation.

Our results suggest that endoperoxide, $\mathrm{N}-89$, is a new antimalarial candidate against drug resistant malaria.

\section{B-29) A PUBLIC/PRIVATE PARTNERSHIP AMONG THE JAPANESE PHARMACEUTICAL INDUSTRY, THE GOVERNMENT AND WHO/TDR (JPMW) : A RESEARCH PROJECT FOR DISCOVERY OF NEW ANTIMALARIAL DRUGS IN JAPAN}

\author{
KAZUHIKO HATA ${ }^{1}$, KAZUHIKO OTOGURO², HARUKI YAMADA ${ }^{3}$ AND SATOSHI ŌMURA ${ }^{3}$ \\ JPMW Coordination Center ${ }^{1}$, Research. Center for Tropical Diseases, Kitasato Institute ${ }^{2}$, \\ Kitasato Institute for Life Sciences, Kitasato University ${ }^{3}$
}

The JPMW project was established in October 1999 through a "public/private parthership" (PPP) among the Japanese Pharmaceutical Companies, Ministry of Health, Labour and Welfare, Japan (MHLW), and WHO/TDR, in order to discover new type of antimalarial drugs in Japan by the Japanese efforts. This project is expected to run for five years. Research Center for Tropical Diseases, The Kitasato
Institute, is identified as the screening center for the project under WHO contract as the Kitasato Screening Center (KSC). KSC is carrying out the evaluation of antimalarial activity for the compounds from the chemical libraries of 14 Japanese companies, along with some of its own natural products, both in vitro and in vivo, using the multi-drug resistant strain of Plasmodium falciparum and the rodent ma- 
laria model, respectively. In many ways the JPMW project was nurtured in the context of such international initiatives as the Roll Back Malaria Initiative that was proposed by WHO in 1998 and the Hashimoto Initiative that was proposed by the Government of Japan in the same year.

The financial support to the KSC screening operations is granted from MHLW through WHO/TDR technical service agreements (Principal investigator: Ōmura, S. ) An entity called JPMW Coordination Center (JCC) is playing a key interface role as "the hub" in this project. By 31 May 2001, KSC has assayed 9,212 samples as in vitro screening. The results have been registered into WHO/TDR database, and individual companies were notified. Furthermore, KSC has assayed 32 compounds as in vivo screening by 31 May 2001. Out of these the KSC results showed 3 compounds that had an activity score 3 in vivo.

In this presentation, we report the background, systems and current status of this JPMW project. There is not many successful cases of public/private partnerships in the world. The fact that this project has been strategically supported by the International Affairs Division of MHLW and blessed by the Japan Pharmaceutical Manufacturers Association (JPMA) would mean that JPMW was recognized as a uniquely Japanese contribution to a major international technical cooperation scheme. Further, we think that it is possible for the development of the new anitimalarial drugs in Japan, going beyond the screening project. The Medicines for Malaria Venture (MMV) is taking an active note of the JPMW outcome.

\title{
B-30) BOTH MOSQUITO-DERIVED XANTHURENIC ACID AND A HOST BLOOD-DERIVED FACTOR REGULATE GAMETOGENESIS OF PLASMODIUM IN THE MIDGUT OF THE MOSQUITO
}

\author{
MEIJI ARAI ${ }^{1,2}$, OLIVER BILlKER ${ }^{2,3}$, HOWARD R. MORRIS ${ }^{4}$, MARIA PANICO ${ }^{4}$, MELAINE DELCROIX 4 , \\ DARREN DIXON 5 , STEVEN V. LEY ${ }^{5}$ AND ROBERT E. SINDEN ${ }^{2}$ \\ Department of Medical Zoology, Jichi Medical School, \\ Department of Biology ${ }^{2}$ and Department of Biochemistry ${ }^{4}$, Imperial College of Science, Technology and Medicine, London, UK, \\ Abteilung Molekulare Biologie, Max-Planck-Institut fur Infektionsbiologie, Berlin, Germany ${ }^{3}$, \\ Department of Chemistry, University of Cambridge, Cambridge, $\mathrm{UK}^{5}$
}

Gametogenesis of Plasmodium in vitro can be induced by the combined stimulus of a $5^{\circ} \mathrm{C}$ fall in temperature and the presence of xanthurenic acid (XA). In vitro experiments showed that $P$. gallinaceum $\left(\mathrm{EC}_{50}=80 \mathrm{nM}\right)$ is much more sensitive to XA than P. berghei $(9 \mu \mathrm{M})$, P. yoelii $(8$ $\mu \mathrm{M})$, and $P$. falciparum $(2 \mu \mathrm{M})$. However, in the mosquito vector we do not know whether the temperature shift and $\mathrm{XA}$ are the only gametocyte activating factors (GAF), nor do we know with certainty the true source (s) of XA in the mosquito blood meal. Previous studies indicate that XA is the only source of GAF in the mosquito. By defining, and then contrasting, the ability of an XA-deficient mutant of Aedes aegypti, with the wild type mosquito to support exflagellation and ookinete formation in vivo, we determined the roles of parasite-, mosquito- and host blood-derived GAF in the regulation of gametogenesis of $P$. gallinaceum. Removal of both host and vector sources of GAF totally inhibited both exflagellation and ookinete production, whilst the lack of either single source resulted in only a partial reduction of exflagellation and ookinete formation in the mosquito gut. Both sources can be effectively replaced/substituted by synthetic XA. This suggests 1) both mosquitoand vertebrate-derived factors act as GAF in the mosquito gut in vivo; 2) the parasite itself is unable to produce any significant GAF activity. Studies are underway to determine whether vertebrate-derived GAF is XA. This data may form the basis of further studies of the development of new methods of interrupting malarial transmission. 


\title{
B-31) STUDIES ON MALARIA MICRO-GAMETOCYTE EXFLAGELLATION INDUCING FACTOR IN THE SALIVARY GLAND OF ANOPHELES STEPHENSI
}

\author{
HIROYUKI MATSUOKA, MAKOTO HIRAI, WANG JiCHUN, SHIGETO YOSHIDA, AKIRA ISHII
}

Department of Medical Zoology, Jichi Medical School

During blood feeding, the salivary glands of Anopheles stephensi extremely reduces protein contents. We investigated midgut contents and prediuresis fluid of An. stephensi. In the midgut contents after full blood meal, we found some proteins reacted with rabbit anti-salivary gland serum, which did not react with the midgut contents of mosquitoes before feeding. This suggests that these proteins come from the salivary glands. After feeding we also found sporozoites in prediuresis fluid of An. stephensi, which had been infected with plasmodium berghei. These sporozoites may come from the salivary glands, because the density of sporozoites in prediuresis fluid correlated with the number of sporozoites in the salivary glands. These results indicate that An. stephensi mosquitoes draw back their own saliva into their midguts when they feed blood (Med Entomol Zool 51: 13-20, 2000).

We next found gamete activation factor (GAF), which in- duced exflagellation of Plasmodium microgametes, in the salivary glands of An. stephensi. The exflagellation was induced in a concentration-dependent manner in the supernatant of salivary gland's crude homogenate. Total amount of GAF in the salivary gland was higher than that in the midgut and the head. GAF in the salivary glands was heat stable and low molecule ( $<3,000$ molecular weight). Analysis of the supernatant by capillary electrophoresis and UV absorbance profile showed that the salivary glands contained xanthurenic acid, which was previously identified as GAF in the head of An. stephensi. The exflagellation inducing activity in the salivary gland declined immediately after a blood meal, implying that GAF was in the saliva, and was delivered into the midgut together with the blood and induced exflagellation in the midgut (Biochem Biophys Res Commun 287: 859-864, 2001). 